Energy Division

\title{
EVALUATING THE WEATHERIZATION ASSISTANCE PROGRAM IN YOUR STATE:
}

\section{A MANAGER'S GUIDE}

Linda G. Berry

Martin Schweitzer

February 2000

\author{
Prepared by \\ Oak Ridge National Laboratory \\ Oak Ridge, TN 37831-6205 \\ managed by \\ UT-Battelle, LLC \\ for the \\ U.S. DEPARTMENT OF ENERGY \\ under contract number DE-AC05-00OR22725
}

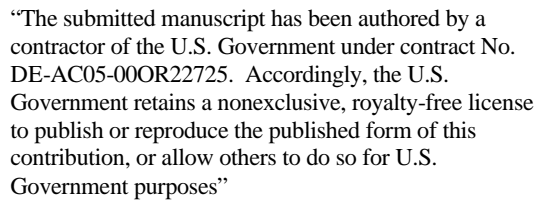

"The submitted manuscript has been authored by a contractor of the U.S. Government under contract No. DE-AC05-00OR22725. Accordingly, the U.S.

Government retains a nonexclusive, royalty-free license

to publish or reproduce the published form of this

contribution, or allow others to do so for U.S.

Government purposes" 


\section{Table of Contents}

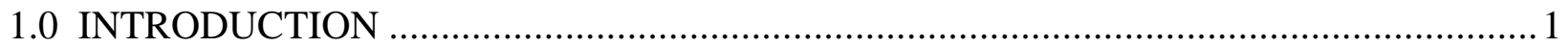

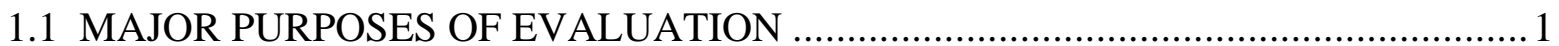

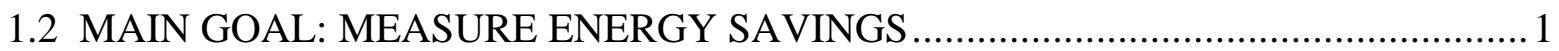

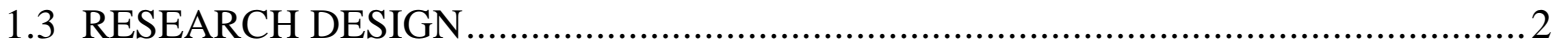

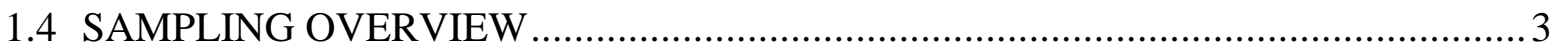

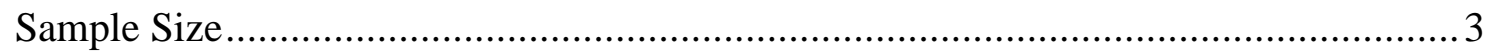

Selecting a Representative Sample.................................................................... 3

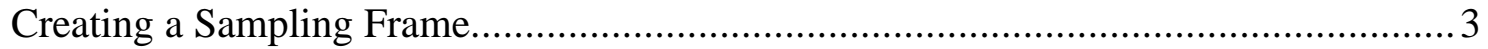

Data Quality Screening ................................................................................. 4

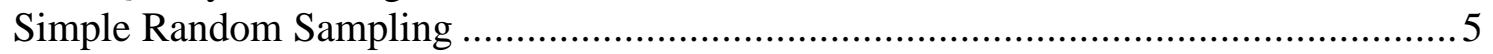

Stratified Random Sampling .............................................................................

1.5 TWO RECOMMENDED WEATHER-ADJUSTMENT AND ANALYSIS TOOLS:

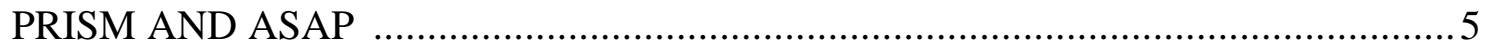

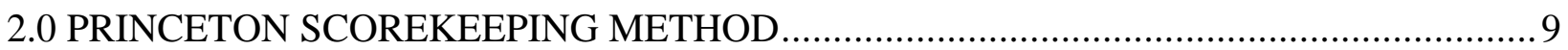

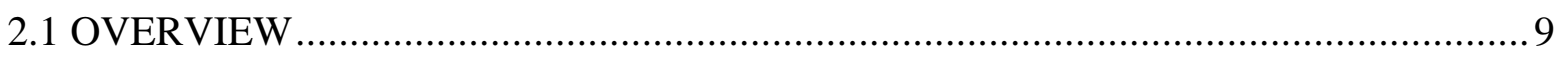

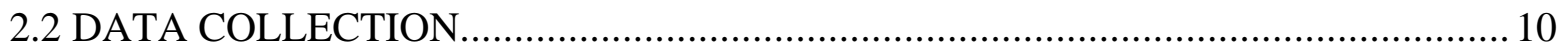

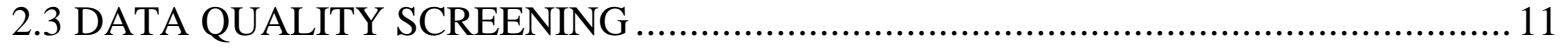

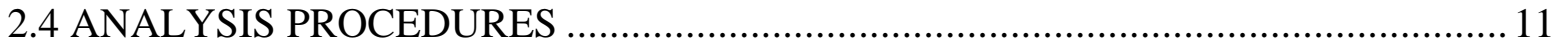

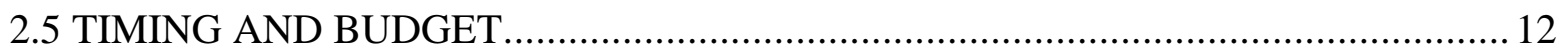

2.6 PRISM USER AND ORDERING INFORMATION ................................................. 13

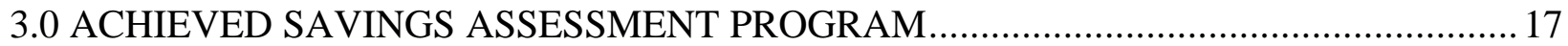

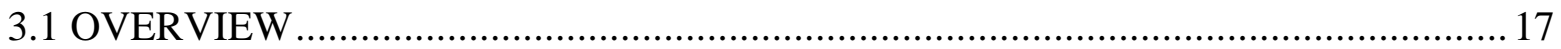

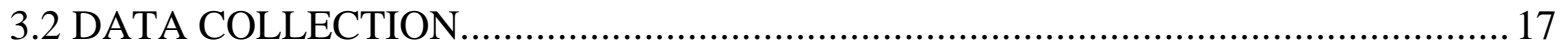

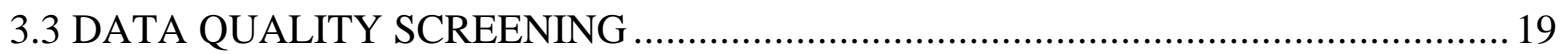

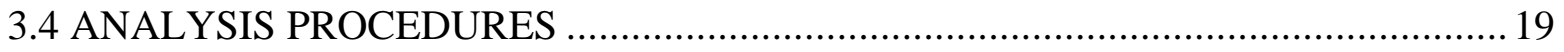

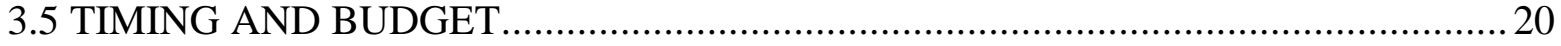

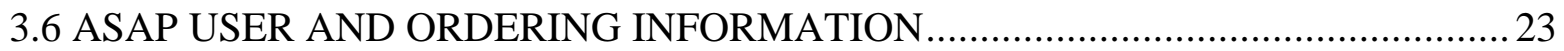

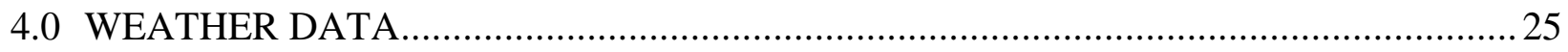

4.1. DATA NEEDED FOR PRISM AND ASAP ANALYSES ………........................ 25

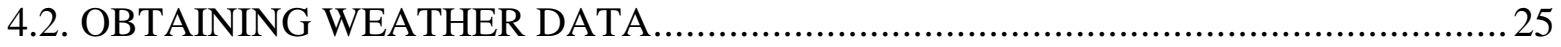

4.3. CLEANING AND FORMATTING WEATHER DATA ........................................... 26

5.0 SAMPLE SIZES FOR EVALUATIONS OF STATE WEATHERIZATION

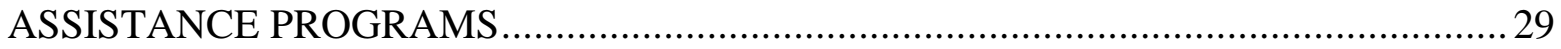

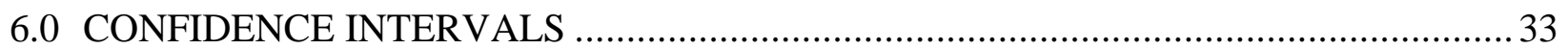

7.0 DETERMINING THE COST EFFECTIVENESS OF WEATHERIZATION

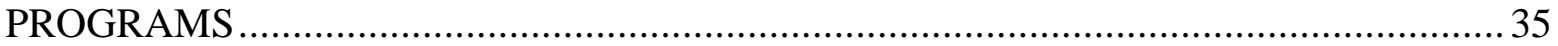

7.1 NET PRESENT VALUE AND BENEFIT/COST RATIO …………………............. 37 
7.2 THREE PERSPECTIVES

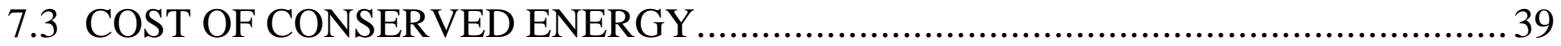

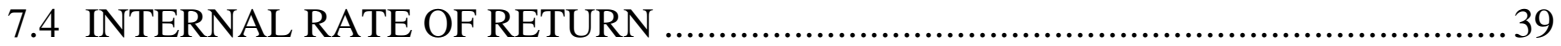

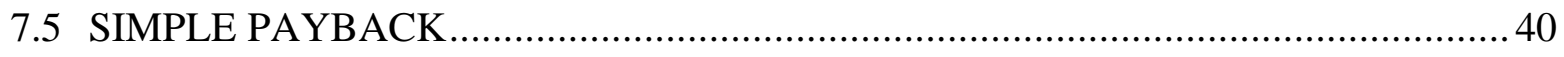

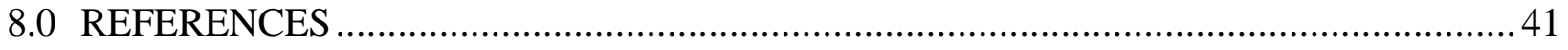

APPENDIX A: STATE EVALUATIONS USED IN 1996 METAEVALUATION

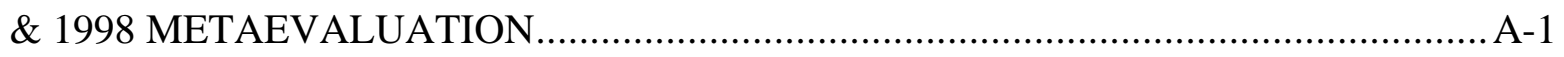

APPENDIX B: TABLE OF CONTENTS FROM PRISM USER'S MANUAL ....................... B-1

APPENDIX C: TABLE OF CONTENTS FROM ASAP USER'S MANUAL ......................... C-1 


\section{LIST OF TABLES}

Table 1. Comparison of the Advantages and Disadvantages of ASAP and PRISM ................8

Table 2. "Heating Models" Table Produced by DESLog Shows Changes in Reference Temperature and Heating Slope Following Weatherization................................. 20

Table 3. Example of DESLog Summary Table .................................................... 21

Table 4. Actual Sample Sizes and Results from Four Recent State-Level Evaluations ........... 31

Table 5. Illustration of How Increased Sample Size Produces Increased Precision and of How Decreased Sample Size Produces Decreased Precision ................................. 31

Table 6. Recommended Economic Parameters for Cost-effectiveness Calculations ............... 36

\section{LIST OF FIGURES}

Figure 1. Waiting list control group design. ........................................................... 3

Figure 2. Conceptual diagram showing major inputs and outputs associated with PRISM

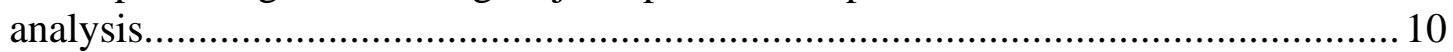

Figure 3. Example of data collection schedule for a PRISM study ................................. 14

Figure 4. Sample form for eliciting customer billing records................................... 15

Figure 5. Sample customer permission form ....................................................... 16

Figure 6. Conceptual diagram showing major inputs and outputs associated with ASAP

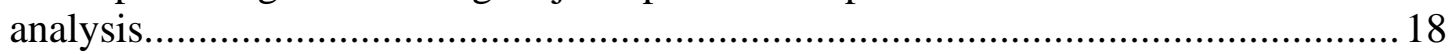

Figure 7. Sample data logger tracking sheet....................................................... 24

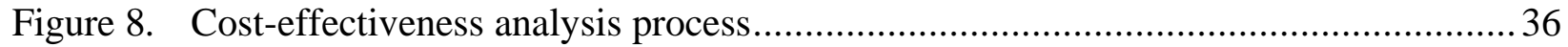

Figure 9. Three perspectives used to calculate cost effectiveness ....................................... 38 


\section{EVALUATING THE WEATHERIZATION ASSISTANCE PROGRAM IN YOUR STATE: A MANAGER'S GUIDE}

\subsection{INTRODUCTION}

\subsection{MAJOR PURPOSES OF EVALUATION}

Evaluations of the Weatherization Assistance Program (the Program) serve three major purposes:

- to document the energy savings and cost effectiveness of the Program,

- $\quad$ to attract and maintain funding, and

- $\quad$ to identify opportunities for improving the Program's performance.

State managers need detailed and specific information about the performance of their own Program if they are to conduct and market it as effectively as possible.

\subsection{MAIN GOAL: MEASURE ENERGY SAVINGS}

In this evaluation guide, we focus almost entirely on the issues related to the measurement of energy savings. Because the Program's main goal is to reduce the energy use and energy burden of low-income households, the minimum output of an evaluation study should be an estimate of energy savings. If resources are limited, the first priority is to obtain this estimate of savings. Some states may be interested in other issues such as determining Program cost effectiveness, testing the value of various audit types, or identifying the best opportunities for increasing energy savings. Because of limited resources, most will focus only on measuring energy savings.

A large number of evaluations that measure energy savings have been conducted at the state-level since the Program began in 1976 (See Appendix A for a list of recent evaluations by state). In addition, a comprehensive National Evaluation of the Program was completed in 1994 for the U.S. Department of Energy by Oak Ridge National Laboratory. This National Evaluation produced a number of process and impact evaluation reports for a variety of issues and fuel types (Mihlmester et al. 1992; Brown et al. 1993a; Brown, et al.1993b; MacDonald 1993; Power et al. 1993; Ternes and Levins 1993; Brown et al. 1994; Berry and Brown 1994; Eisenberg et al. 1994). Updates of the National Evaluation findings on energy savings and cost effectiveness were completed in 1997 and 1998 by conducting two metaevaluations of state-level studies. The first of the metaevaluations used the state-level evaluations that became available from 19901995 (Berry 1997; Berry, Brown and Kinney 1997). The second metaevaluation was based on evaluations completed between 1996 and August of 1998 (Schweitzer and Berry 1999).

Although many Program evaluations are available, along with a substantial literature on how to conduct them, there is a continuing need for up-to-date Program evaluations. We know 
that, in the past, Program energy savings varied greatly across dwelling types, agencies and climatic regions as well as over time. There is every reason to expect that Program performance will continue to vary along these dimensions in the future. Program performance also is likely to improve as technical innovations and enhanced program management procedures are adopted.

\subsection{RESEARCH DESIGN}

Research designs are aimed at isolating the effect of the Program from all other factors that could produce changes in energy consumption. The logical problem is to determine the difference between the energy savings actually achieved by Program participants and the savings that they would have realized had there been no Program. The second term of what their savings would have been if there had been no Program cannot, of course, be measured directly. Because it is impossible to determine exactly "what would have happened if . . " the challenge is to design a comparison that approximates this situation. Designing a standard of comparison is essentially developing a plan for collecting evidence that gives one confidence that the observed effects on client energy consumption were indeed caused by the Program and not some other factor.

It is important to remember that it is always possible that some factor other than the Program treatment itself produced the observed changes in the weatherized homes. To accurately measure the fuel savings produced by the Program treatment, it is important to control the key confounding factors, which are changes in weather patterns, fuel prices, and occupant behavior. Weather effects on consumption can be controlled with statistical techniques that produce weather-normalized measures of fuel use. Both the Princeton Scorekeeping Method (PRISM) and the Achieved Savings Assessment Program (ASAP) software packages, which are explained in detail in Sections 2.0 and 3.0, contain such weather normalization procedures.

The influences of occupant behavior, fuel price changes and other possible confounding factors, are best controlled by comparing the consumption changes in two equivalent groups of households. One of these groups (the treatment group) receives Program services during the study period while the other set of households (the control group) does not. If the treatment and control groups are equivalent, then any post-treatment differences in their energy consumption can be validly attributed to the Program's influence.

The most practical basic pre-test, post-test design for weatherization evaluations is shown in Figure 1. This design is a waiting list design where the control group eventually receives Program services, but at a later date than the treatment group. Changes in weather-adjusted consumption during the time period after the treatment group receives retrofits, but before the control group receives services, are the measure of Program impact. This design is often used in Weatherization Assistance Program evaluations. 


\begin{tabular}{llll}
\hline & $\mathrm{T}^{\mathrm{a}}$ & $\mathrm{T} 2$ & $\mathrm{~T} 3$ \\
\hline Treatment group & $\mathrm{O}_{\mathrm{e}}$ & $\mathrm{X}$ & $\mathrm{O}_{\mathrm{e}}$ \\
Control (waiting list) group & $\mathrm{O}_{\mathrm{e}}$ & $\mathrm{O}_{\mathrm{e}}$ & $\mathrm{O}_{\mathrm{e}}$ \\
\hline
\end{tabular}

${ }^{\mathrm{a}} \mathrm{T} 1-3$ = time periods for measuring energy consumption

$\mathrm{O}_{\mathrm{e}}=$ energy consumption record;

$\mathrm{X}=$ weatherization measures installed

Figure 1. Waiting list control group design.

\subsection{SAMPLING OVERVIEW}

Sample Size. In most cases, a state-level evaluation of energy savings should be based on a sample of at least 350 weatherized homes and 350 control homes (See Section 5.0 on sample size for more detail). Because sample attrition due to poor data quality often runs as high as $50 \%$, it is desirable to begin with a sample of about twice this size if possible. If sample sizes fall below 350, an estimate of savings can still be obtained, but the confidence interval (See Section 6.0 on confidence intervals) on this estimate may be so large that no meaningful conclusion about the true level of Program performance can be reached.

Selecting a Representative Sample. The selection of a representative sample of houses is an important step in conducting a credible evaluation. Only a representative sample makes it possible to generalize to the population of interest, which in state-level evaluations is generally the whole state Program. Obviously, if only a few handpicked agencies, or only the dwellings weatherized by the most experienced crews, are studied, the findings will not represent the whole state's performance.

Creating a Sampling Frame. The first step in selecting a representative sample is to construct a sampling frame, which is simply a list of all of the dwellings weatherized during the study period that meet the criteria for inclusion in the study's population. Often, a study's population is restricted to homes that heat with only natural gas or electricity because it is possible to obtain utility billing records for these heating fuel types. This restricted sampling frame works well only if the majority of homes in the state use these fuels. Natural gas heat is used in more than half of homes nationally, and by a large majority of homes in many states. Depending upon the distributions of heating fuel types that characterize the client homes in your state, you should decide whether or not restricting the sample to natural gas and electric heat is reasonable. If fuel oil, propane, and/or some other types of fuel are used for heating in large proportions of the client homes in your state, then houses that heat with these common fuel types should be included in the evaluation's sampling frame too. 
If fuel types other than natural gas and electricity predominate in a state, then they must be studied with data from sources other than utility billing records. When this is necessary, more complicated data collection procedures must be implemented. Either metering of heating systems, or client and vendor cooperation in keeping records of fuel purchases, becomes necessary. Nearly all state-level evaluations to date have studied only homes that heat with natural gas (or electricity in a few states) because of the extra expense and difficulty of collecting data on the use of other types of fuels.

Data Quality Screening. Ideally, screening for some data quality characteristics will take place before putting a dwelling on the list of households eligible for inclusion in the study. It is not essential, and not always possible, to perform data quality screening before creating a sampling frame. When it is possible, however, it is desirable, because it will reduce the amount of sample attrition and the effort of data collection and cleaning.

If the data quality checks cannot be made before drawing the sample, then the initial sample size should be increased. In this case, the standard quality checks should be performed as the study progresses. The houses that do not meet the checks then should be dropped from the sample before performing the final analysis of energy savings. There are five standard data quality checks:

- First, are energy consumption records available for the entire pre-weatherization period. If these pre-treatment period records cannot be obtained, there is no point in including the dwelling in the sampling frame, nor in expending any effort in trying to collect posttreatment records.

- Second, does the dwelling use supplementary heating sources such as electric or kerosene space heaters, or wood stoves. When supplemental heat is used it becomes extremely difficult to separate the effects of weatherization from the effects of behavioral changes related to fuel use. Several studies, for example, have suggested that because of the labor involved in using wood, other fuels will be substituted when attaining the same comfort level becomes more affordable (Tonn and White 1986). The easiest strategy is to include only homes with no supplemental heat in the sample. If homes with supplemental heat are included, then it will be necessary to collect and analyze data on their use of supplemental fuels to obtain accurate results.

- Third, were weatherization measures installed independent of the Program during the study period. When this occurs a meaningful pre- and post-treatment period for the Program is unlikely to be available and the house should be dropped.

- A fourth check is for change in occupancy (i.e., a new family moved into the dwelling). A change in the number of occupants and in their behavior may change consumption patterns more than the Program treatment. Therefore, it is best to remove dwellings with occupancy changes from the study. 
- The final check is for changes in family composition. When a new baby is added to the family, or teenagers leave home, effects on energy use can be so large that they mask Program effects. Again, removing dwellings with these changes from the study is the easiest solution.

Simple Random Sampling. Once a list of dwellings that meet the study criteria is ready, selecting a random sample is straightforward. First, number the list of all of the dwellings that meet the study criteria. Second, decide on the sample size that you will use (See Section 5.0 on Sample Size for guidelines). Third, use a random number table to select dwelling numbers until the desired sample size is reached. Spreadsheet programs such as Microsoft Excel have random number generator functions that will produce a list of random numbers. Alternatively, many statistics textbooks include tables of random numbers. Simply go down the list of random numbers and pick the corresponding dwelling from the numbered list until the desired sample size is reached.

Stratified Random Sampling. It may be desirable to select a set percentage of dwellings from several strata (subgroups) of interest. For example, the sample could be stratified by climate region, dwelling type, heating fuel, or some other variable. Creating strata before sampling ensures that the subgroups of interest are adequately represented. You may wish to see how savings vary by housing type: single-family site built homes versus mobile homes, for instance. In this case, two numbered lists (one list for each housing type) would be prepared and the dwellings to be included in the study would be selected at random from each list. Each subgroup studied should meet the minimum sample size requirements in order to obtain accurate estimates of energy savings for that subgroup.

\subsection{TWO RECOMMENDED WEATHER-ADJUSTMENT AND ANALYSIS TOOLS: PRISM AND ASAP}

Until recently, most Program evaluations determined energy savings by comparing weather-normalized utility billing data for a pre- and post-retrofit year. The method of choice for evaluations based on utility billing data is the Princeton Scorekeeping Method (PRISM). PRISM is a standard methodology, which was developed and tested extensively by statisticians at Princeton University in the mid-1980's. It is available as a stand-alone software package with a complete instruction manual (See Section 2.0 and Appendix B for more details). It is a statistical procedure that normalizes for weather by adjusting fuel consumption to a normal weather year (defined as the 12 to 30 year average of the daily temperature for each day of the year). By statistically adjusting the actual fuel consumption level for both the pre- and post-weatherization years to what it would have been in a year of normal (or average) weather, PRISM removes the effect of weather from the estimate of energy savings (which is calculated by subtracting weather-normalized consumption in year two from weather-normalized consumption in year one). In addition to the total consumption values, PRISM identifies the components of baseload (non-weather dependent) consumption and of heating (weather-dependent) consumption of the primary heating fuel. It also provides a number of statistical indicators of regression model quality and reliability, such as the model $\mathrm{r}^{2}$ and the standard errors of each model component. PRISM, which has been used in several hundred studies, is usually applied to homes that heat 
with natural gas and/or electricity because utility billing records are available only for these fuels. When records of purchases can be obtained, however, PRISM can be used for homes that heat with fuel oil or propane.

Because of the high cost, and the greater effort, associated with installing metering equipment instead of relying on billing records, this method typically has been applied only to small samples of homes. In the past, full-scale statewide or nationwide evaluations have relied exclusively on billing data analyzed with PRISM, or with some similar regression model. Today, however, metering equipment, like most electronic equipment, is becoming much cheaper than it was previously. Run-time meters for heating systems now are available for about $\$ 250-\$ 350$ each. Although it is still more costly to use metering equipment than it is to collect billing data, it is now becoming feasible for state Program managers to use metering for samples of sufficient size to characterize statewide energy savings. Another reason that metering is now easier to implement is that software designed specifically for the evaluation of the Program with data from run-time meters has been developed and is available at a nominal cost (only the cost of materials) from the Minnesota Weatherization Assistance Program office (See Section 3.0 for more information).

The Minnesota Program, in cooperation with the University of Minnesota, conducted a pilot program in 1996 that incorporated metering of heating system run times into routine procedures in three agencies. This pilot effort tested an equipment and software package (the Achieved Savings Assessment Program or ASAP, which includes DESLog software for weatheradjustment and statistical analysis), that downloads run-time data collected from meters installed on heating systems. After the run-time data are downloaded from the meters and weather data inputs are entered, DESLog performs the analysis of weather-adjusted energy savings. Today ASAP has been introduced into the routine operations of all of Minnesota's local agencies. A few other states have experimented with ASAP on a small scale, but only Minnesota has implemented it statewide.

Although, for samples of equal size, the use of ASAP is still initially more expensive than the use of PRISM, there are compelling reasons to consider it both as an evaluation method and as a program management strategy. When short-term metering is made part of routine program operation, it becomes possible to produce immediate improvements in energy savings. The ASAP approach not only measures overall Program performance as PRISM does, but it also provides timely house-specific feedback on savings. Because these house-specific results become available in about six weeks time, crews can return to the homes that did not produce the predicted savings. With on-site inspections, Minnesota's Program managers report that their workers usually can identify and often can correct the underlying problems that are interfering with the achievement of savings. As a result, the staff of the Minnesota Program considers ASAP to be a powerful training and quality control tool.

PRISM, and similar regression methods, are a reliable and, initially, less expensive way to measure energy savings for large samples of homes, but they do not produce results for more than a year after weatherization takes place. By then, it may be too late to return to homes or to correct the problems that are interfering with energy savings. The pilot study in Minnesota estimated that the use of metering equipment with ASAP added an average of about one extra 
day to the time spent on weatherizing each home. Now that Minnesota is in the phase of fullscale implementation, with the initial ASAP learning experiences behind them, the average added time per house due to ASAP is closer to two hours. This extra time (along with the startup time commitment and the initial cost of the metering equipment, computers and software) is a substantial investment, but the benefits also are substantial. With the use of the ASAP system, the routine measurement and improvement of energy savings as well as an opportunity for highly effective training experiences all are provided by the same set of procedures. Another advantage of the ASAP approach is that it is easily applied to heating systems that use fuel types for which utility billing records are not available. It is not necessary to rely exclusively on ASAP or PRISM. Each method could be applied to different subsets of houses, if one desires, or even to the same houses if one wishes to measure impacts on more than one fuel simultaneously.

The goal of this evaluation guide is to provide state Program managers with the information they need to decide on the best evaluation strategy for their state. More details on the two recommended approaches (PRISM and ASAP) are provided in Sections 2.0 and 3.0 of this report. An overview of the key advantages and disadvantages of each approach is presented in Table 1. Section 4.0, 5.0 and 6.0 deal with weather data, sample size and confidence intervals. Section 7.0 presents information on methods of determining cost effectiveness. 


\section{Table 1. Comparison of the Advantages and Disadvantages of ASAP and PRISM}

\section{Advantages of PRISM}

- Almost 20 years of experience: reliable, wellunderstood, well developed

- A standard technique: used in many evaluations

- Less expensive per house than ASAP so can use larger samples

- Minimal demands on state and local Weatherization staff because can be entirely subcontracted

- Measures all end-uses that are present* for the fuel(s) being studied
- Faster Feedback

- 4 to 6 weeks post-weatherization for a house

- less than one year for a state

- Much easier to use for unmetered heating fuels (e.g. propane, oil) and is easily used for gas or electric heating too

- No cooperation needed from gas and electric utilities or any other groups because it is done entirely by Weatherization Program Staff

- Ongoing Quality Control System

- Training value

- Opportunity to identify homes with less savings than expected and often to correct the problems identified

- Becomes easier to use and less costly with experience

- $\quad$ Can use same equipment, software and procedures to perform on-going evaluations in a sample of houses for every heating season, if desired

\section{Disadvantages of PRISM}

- Slow, at least two, and probably three, years to complete

- Depends on the cooperation of gas and electric utilities (or other fuel vendors)

- Lacks the more rapid quality control and feedback features of ASAP

- Experience does not significantly reduce the costs or difficulty because $75 \%$ of the effort is devoted to data collection and cleaning which must be done from the beginning each time a new evaluation is performed

- Harder to deal with fuels, other than natural gas or electricity, that are not metered by utility companies

\section{Disadvantages of ASAP}

- Meters are expensive so is hard to get large enough sample initially

- $\quad$ Start-up is time consuming

- Heavy demands on staff time and skills at first

- Training required for several people per agency

- Cannot subcontract

- Measures only heating system use; does not measure cooling or other end-uses

- Hawthorne effects are a potential concern**

*In the case of natural gas this includes gas heating, and in many homes, may include gas water heating and/or cooking. In the case of electricity, lighting and electric appliances will always by included in the electric bill. When air-conditioning equipment and/or electric heat are present their use will, of course, be included in the electric billing records as well.

**The Hawthorne effect is defined as the tendency to change one's behavior simply because one knows that one is being observed. Although this effect certainly may be a problem in ASAP-based studies, where both the Weatherization crews and the clients know they are being observed, the authors are unaware of any evidence demonstrating the magnitude, or even the existence of, the Hawthorne effect in metering-based evaluations of the Weatherization Assistance Program. 


\subsection{PRINCETON SCOREKEEPING METHOD}

\subsection{OVERVIEW}

PRISM is a computer software system for quantifying the energy savings resulting from building weatherization activities. The name of this system, which was developed by researchers at Princeton University, is an acronym for PRInceton Scorekeeping Method. The major inputs to a PRISM analysis are:

- daily temperature data for the study area;

- long-term degree days for the same region, based on the above-mentioned temperatures ${ }^{1}$; and

- monthly billing data for each structure studied for approximately one year before and one year after weatherization.

The major output is normalized annual consumption (NAC) for the pre-weatherization and post-weatherization period for each building included in the study. In this context, "normalized" means that annual energy usage for both the pre- and post-weatherization periods is adjusted to reflect average long-term weather conditions for the study area. This allows energy savings to be calculated accurately, without the confounding effect that would otherwise arise from variations in temperatures - and the associated heating and cooling needs-during the pre- and post-weatherization periods. PRISM also can combine the findings from all the individual structures studied, including a non-weatherized control group, and calculate average savings for the entire group of weatherized buildings. Fig. 2 is a conceptual diagram showing the major inputs and outputs associated with a PRISM analysis, both for individual structures and an entire group of buildings. Additional information on using PRISM is provided by the PRISM Users' Guide (Fels, Kissock, Marean, and Reynolds, 1995) and the many articles that have been written on this system (e.g., Fels 1986; Fels, Kissock, and Marean 1994; Fels and Reynolds 1990; Goldberg 1986; Hirst 1986).

\footnotetext{
${ }^{1}$ Degree days are the difference between the mean temperature for any given day and a given reference temperature, which represents the point at which a building begins using its heating and/or cooling system. There are both heating and cooling degree days, although only one or the other might be relevant for any given fuel type and structure. PRISM calculates building-specific heating and/or cooling reference temperatures for each structure studied, reflecting the individual energy consumption profile of the building in question.
} 

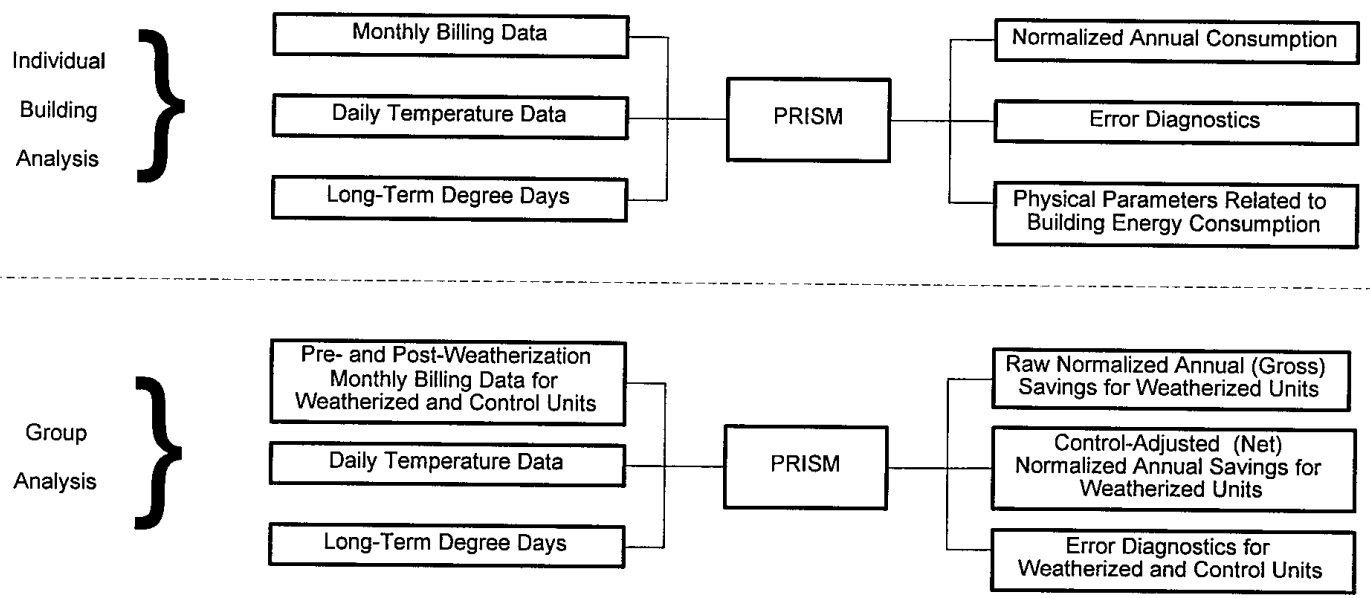

\section{Figure 2. Conceptual diagram showing major inputs and outputs associated with PRISM analysis.}

Source: Fels, 1986; Fels and Reynolds, 1990.

\subsection{DATA COLLECTION}

The major inputs that a user must supply in order to perform a PRISM analysis are longterm daily temperature data for the study area and monthly billing records for each structure studied. Each of these items is discussed separately below. Long-term degree days, while necessary, will be calculated by PRISM for each building, based on the daily temperature data provided by the user.

Daily temperature data must be provided for the study period (generally 12 months before and 12 months after building weatherization) as well as for a sufficiently long period preceding weatherization to allow the calculation of average annual degree days to use in the normalization process. The PRISM designers recommend that at least 12 years of daily temperature data be provided. The weather files must show the year, month, and number of days in each month, along with the daily temperatures. The National Climatic Data Center of the National Oceanic and Atmospheric Administration (NOAA) in Asheville, NC, is an excellent source of these data (see Section 4.0 on Weather Data for ordering information). Temperature data should be collected for the major weather stations that are closest to the weatherized buildings. If the structures under study cover a broad geographic area (e.g., an entire state), then temperature data should be gathered for multiple weather stations and each house should be matched with the nearest major station.

Monthly billing records must be collected for the fuel or fuels under study. For each structure studied, the records should identify the building and indicate its energy consumption units (e.g., kWh of electricity; cubic feet of natural gas; gallons of fuel oil). If multiple fuels are 
used in a single building, distinct records should be kept for each fuel. The billing records should show how much energy was consumed during each period between meter readings or refueling and indicate the dates at the beginning and end of each consumption period. Furthermore, the pre-weatherization consumption periods should be clearly distinguished from those following building weatherization. Use of a control group is not mandatory and is not always feasible. However, control group data tend to improve the validity of savings calculations by isolating the changes in energy consumption produced by the weatherization program from those that would have occurred anyway. If a control group is used, the billing records should indicate whether the structure is part of the weatherization group or the control group.

\subsection{DATA QUALITY SCREENING}

The long-term daily temperature data received from NOAA (or another source, such as a local weather station) should be checked for completeness. The PRISM designers recommend that data be used from primary weather stations, which often are located at airports and military bases, because the data are likely to be more complete and have greater accuracy than records compiled at secondary stations. The user should make sure that the data used for each house comes from the closest major weather station.

Missing billing data can reduce the accuracy of PRISM results, particularly if the missing data are from a high-consumption period or there are multiple missing readings. Similarly, estimated billing data (in place of actual meter readings) can lead to questionable results. For this reason, PRISM is designed to identify readings that appear to be estimates (generally indicated by a pair of consecutive readings that are alternately high and low) and gives the user the option of combining them into a single reading covering the entire period in question. Extreme consumption values also can be identified and PRISM can compensate for these by running a "robust" analytical model for these cases. Finally, users can select reliability criteria that allow them to identify and remove from the analysis any structure for which the PRISM model does not appear to be a good predictor of annual energy use.

\subsection{ANALYSIS PROCEDURES}

An evaluator who has never used PRISM can learn to do so in a few days by reading key articles, carefully reviewing the PRISM Users' Guide, and doing the practice tutorials included in the guide. However, the learning process will be greatly facilitated if the would-be user is familiar with regression analysis and associated concepts, such as intercept, slope, standard error, and R-squared values. Someone who is familiar with statistical analysis and windows-based software systems is likely to have an easier time mastering PRISM than someone without such background.

PRISM operates by taking the previously-described temperature data and billing records and producing a regression equation for each building that explains annual energy consumption in terms of a few key physical parameters. These parameters are: (1) the structure's daily baseload, which is the amount of energy it uses that does not vary with outside temperature; (2) the heating and/or cooling slope, which is the amount that energy use increases with each 
additional heating and/or cooling degree day; and (3) the building-specific reference temperature, which is the outside temperature (one for heating and another for cooling) at which the building begins to use energy to raise or lower the indoor temperature. By entering the long-term average annual number of degree days for the same reference temperature(s) into the formula obtained from the regression model, the user produces an estimate of Normalized Annual Consumption.

The formula for NAC for a building that heats and cools with the same fuel can be expressed as follows: $N A C=365 \alpha+\beta_{h} H_{o}\left(\tau_{h}\right)+\beta_{c} C_{o}\left(\tau_{c}\right)$, where $\alpha=$ daily baseload consumption, $\beta_{\mathrm{h}}=$ heating slope $\beta_{\mathrm{c}}=$ cooling slope, $\mathrm{H}_{\mathrm{o}}\left(\tau_{\mathrm{h}}\right)=$ heating degree days for a typical year at reference temperature $\tau_{\mathrm{h}}$, and $\mathrm{C}_{\mathrm{o}}\left(\tau_{\mathrm{c}}\right)=$ cooling degree days for a typical year at reference temperature $\tau_{\mathrm{c}}$.

PRISM has models for heating only, cooling only, and heating and cooling combined. It also has an automated model selection feature that selects the best model for each individual building being examined. This automated selection feature is recommended by PRISM's developers in cases where the fuels under study might be used for both heating and cooling.

PRISM calculates Normalized Annual Savings (NAS) for each building by subtracting post-weatherization NAC from pre-weatherization NAC. In addition, average savings (both median and mean) can be calculated by combining the findings from all structures in the study. Raw energy savings (sometimes referred to as "gross" savings) are calculated from the weatherized buildings alone. Where control group data are available, adjusted savings are determined by subtracting the savings experienced by the control group (which occurred in the absence of program efforts) from the savings that took place in the weatherized structures. While PRISM does not produce an estimate of dollar savings, the user can calculate this relatively easily by multiplying the units of energy saved by unit cost for the year in question.

In addition to estimating NAC and NAS, PRISM also produces error diagnostics that indicate how well the regression model predicts energy consumption. The R-squared statistic and the Coefficient of Variance (CV) indicate model reliability for both the individual building analysis and the group analysis. R-squared indicates the amount of variance in NAC that is explained by the model. For example, an R-squared of 0.95 means that $95 \%$ of the variance in NAC is accounted for by baseload, slope, and degree days. In most cases, PRISM predicts NAC with an R-squared of 0.90 or better. The other key diagnostic is the CV of NAC, which expresses the standard error ${ }^{2}$ of NAC as a percentage of NAC itself. In most cases, this number is less than $5 \%$.

\subsection{TIMING AND BUDGET}

A state-level PRISM based evaluation that focuses primarily on producing an estimate of energy savings will cost approximately $\$ 100,000$ if it is conducted entirely by a professional contracting company. This cost level assumes a sample size of about 500 dwellings, with average

\footnotetext{
${ }^{2}$ The standard error of NAC is a measure of variability calculated by PRISM for each building under study that indicates how reliable the estimate of NAC is. Larger standard errors indicate less reliability.
} 
costs per dwelling for data collection and preparation of about $\$ 150$. The remaining costs are for analysis and overhead.

Doing a good deal of the data collection in-house as part of routine program procedures can lower costs. For example, if fuel consumption records are collected for the preweatherization year as part of the client intake process, this part of the data collection process will be considerably easier and less costly.

About $75 \%$ of the effort in a PRISM study occurs in the data collection, database construction, and data cleaning phases. Once a clean and complete data set is available, analysis costs are relatively small. In the average case, data collection might take about nine months of FTE effort, data entry and cleaning two months (FTE), and analysis one month (FTE).

Because PRISM requires a full year of pre- and post-weatherization fuel consumption data, the data collection effort alone can be spread out over more than two years. A sample data collection schedule for a PRISM study is shown in Figure 3. In general, one can expect a PRISM study to be completed about three years after it begins.

\subsection{PRISM USER AND ORDERING INFORMATION}

An evaluator who has never used PRISM can learn to do so in a few days by reading key articles, carefully reviewing the PRISM Users' Guide, and doing the practice tutorials included in the guide. The Table of Contents from the PRISM Users' Guide is reproduced in Appendix B. In addition to containing introductory information to help a would-be user become familiar with the basics of PRISM, the Users' Guide also includes a Reference Manual that provides detailed information on using PRISM, with separate sections on input files, output files, and all available menus. PRISM comes on two diskettes which can be used on Windows-based personal computers and also on Apple Macintosh computers equipped with a PC-emulator.

The cost schedule for purchasing PRISM software is as follows:

- Universities and Community Action Program agencies: \$395

- Government agencies: $\$ 795$ for first copy and $\$ 395$ for second copy

- Bulk orders (more than five copies): \$795 for first copy and \$195 for other copies

To order PRISM software and manuals, and also to seek technical assistance when using PRISM, one should contact:

Michelle A. Marean

Center for Energy and Environmental Studies (CEES)

Princeton University

Box CN5263

Princeton, NJ 08544-5263

Phone: (609) 258-4677

Fax: (609) 258-3661

e-mail: marean@princeton.edu 
Data Collection Time Periods Covered for Homes Weatherized from April to December 1997

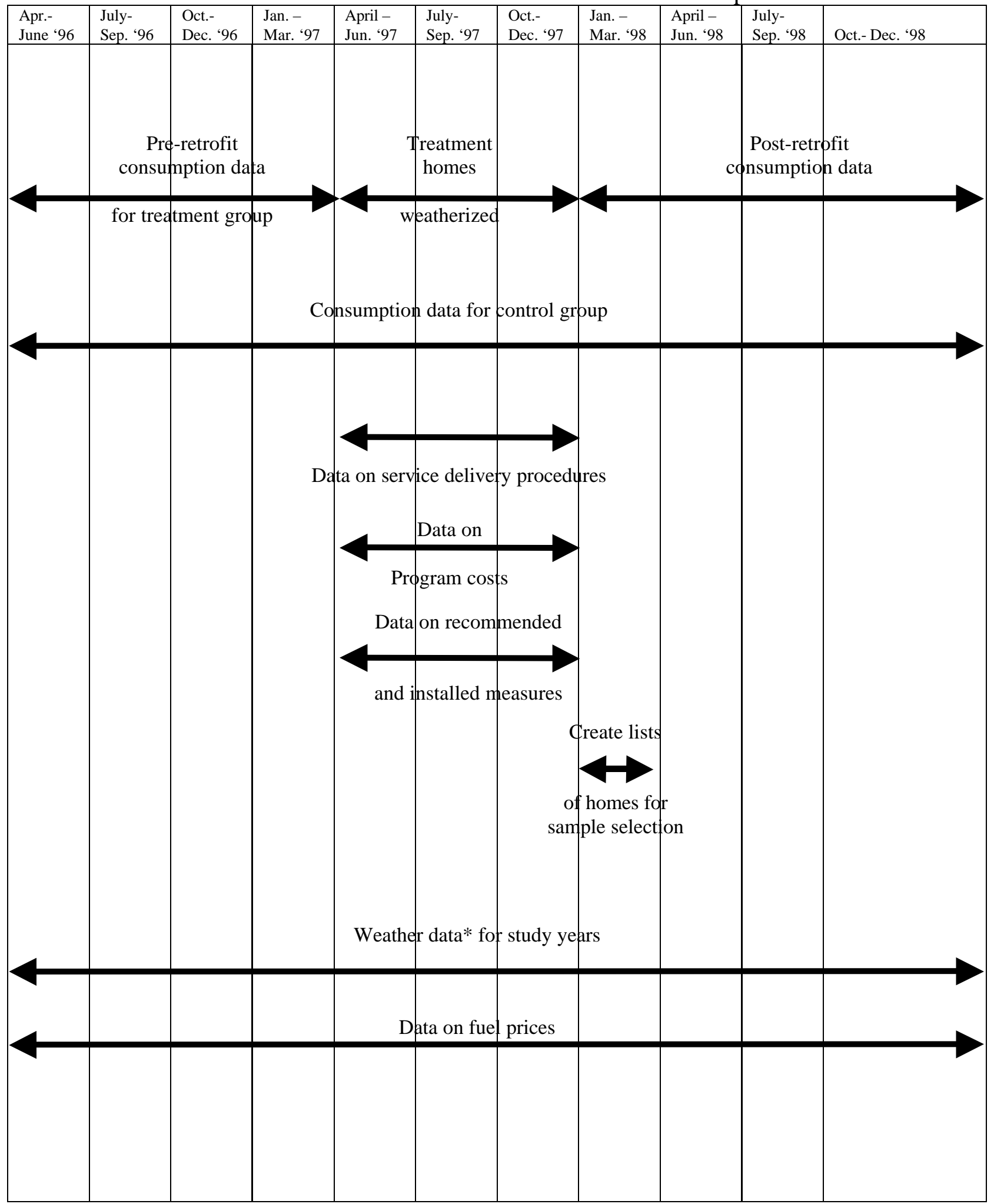

Figure 3. Example of data collection schedule for a PRISM study.

*Daily temperature data for a 12-year period that includes the study years also is needed to calculate long-term average heating and cooling degree days. 
The two major data inputs needed for a PRISM analysis are monthly billing records for each structure studied and long-term daily temperature data for the study area. In order to obtain billing data for the pre- and post-weatherization periods, utilities must agree to provide the records. Often utilities require that customers provide written permission for the release of this information. Figure 4 is an example of a form that can be used to elicit billing records from a utility, and Figure 5 is a sample form that can be used to acquire customers' permission for utility release of their billing records. A discussion of how temperature data can be obtained is provided in Section 4.0 of this report.

Customer Acct \#

Name

Address
Consumption Record

Sample Format: 1998

\begin{tabular}{|c|c|c|c|c|c|c|c|c|}
\hline \multicolumn{5}{|c|}{ ESSENTIAL DATA } & \multicolumn{4}{|c|}{ OTHER DATA } \\
\hline $\begin{array}{c}\text { Time } \\
\text { Period }\end{array}$ & $\begin{array}{l}\text { Billing } \mathrm{I} \\
\text { Beginning Date } \\
\text { mm dd yy }\end{array}$ & $\begin{array}{l}\text { eriod } \\
\text { Ending Date } \\
\text { mm dd yy }\end{array}$ & $\begin{array}{l}\text { Consumption } \\
\text { (Kwh, or ccf, } \\
\text { or therms) }\end{array}$ & $\begin{array}{l}\text { Reading Type } \\
\text { (estimated, } \\
\text { actual, or read by } \\
\text { customer }\end{array}$ & $\begin{array}{c}\text { Total Dollar } \\
\text { Amount } \\
\text { Billed* }\end{array}$ & $\begin{array}{l}\text { Budget } \\
\text { Billing } \\
\text { (yes/no) }\end{array}$ & $\begin{array}{l}\text { Additional } \\
\text { Billing } \\
\text { Codes }\end{array}$ & $\begin{array}{c}\text { Amount } \\
\text { of Customer } \\
\text { Payment (\$) }\end{array}$ \\
\hline $1-98$ & & & & & & & & \\
\hline $2-98$ & & & & & & & & \\
\hline $3-98$ & & & & & & & & \\
\hline $4-98$ & & & & & & & & \\
\hline $5-98$ & & & & & & & & \\
\hline $6-98$ & & & & & & & & \\
\hline $7-98$ & & & & & & & & \\
\hline $9-98$ & & & & & & & & \\
\hline $10-98$ & & & & & & & & \\
\hline $11-98$ & & & & & & & & \\
\hline $12-98$ & & & & & & & & \\
\hline
\end{tabular}

*Please include state and local taxes. Exclude penalties, merchandise, repair, service and late charges. If the household is on the budget plan, do not provide the budgeted bill; provide instead the dollar amount that is the cost of the actual consumption in the period.

Figure 4. Sample form for eliciting customer billing records. 
Long Range Evaluation Plan for the Vermont Weatherization Assistance Program

Appendix A: Sample Fuel Consumption History Release Authorization

VERMONT WEATHERIZATION ASSISTANCE PROGRAM Energy Consumption History Release Authorization

TO:

$\mathrm{I}$, , (name) , (address)

, (town)

do hereby authorize release of my complete energy consumption history for up to two (2) years prior to the date of this authorization, and for any subsequent period thereafter, as necessary for the purpose of determining my energy-efficiency improvement needs and to assist in evaluating the performance of the Vermont Weatherization Assistance Program. I request that the released information include the type of fuel, dates of delivery, the units of fuel delivered on those dates, and either the unit cost or the total cost of the fuel delivered on those dates.

(signed)

(date)

(account number or other identifying information)

The requested information should be sent to the following Weatherization Assistance Program field office:

\begin{tabular}{l} 
Contact \\
Person \\
Phone \\
Number \\
\hline
\end{tabular}

NOTE:

Source: Vermont Energy Investment Corporation

Figure 5. Sample customer permission form. 


\subsection{ACHIEVED SAVINGS ASSESSMENT PROGRAM}

\subsection{OVERVIEW}

ASAP (an acronym for Achieved Savings Assessment Program) is a computer-based system for determining how weatherization activities affect buildings' heating fuel consumption. The system utilizes the SmartLogger CT Logger, which is a portable electronic device that can be attached to a heating system to record when it is in operation (i.e., its "run time"). The run time data collected by the logger is subsequently translated into electronic files using SmartWare data retrieval software. These files, which document daily pre- and post-weatherization heating system run times, are entered into a computer along with a building-specific heating system input

rate (or "firing rate"), which describes how much energy is consumed during each hour of heating system operation. Data on the dollar cost per unit of energy used in the heating system also are recorded, to be used in subsequent calculations of weatherization-induced cost savings. The final inputs required for an ASAP analysis are current daily temperature data and long-term daily temperature files, which allow the computation of annual heating system energy usage for a typical (or "normal") year, both before and after weatherization. The data analysis is performed by computer using DESLog, a software program developed for the Weatherization Program of Minnesota's Department of Economic Security (DES). DESLog operates in conjunction with the Microsoft Excel spreadsheet program. Figure 6 illustrates the major inputs and outputs associated with an ASAP analysis. Additional information on using this system is provided in the User's Manual for ASAP, Featuring DESLog (Minnesota Office of Low-Income Energy Programs 1998) and several other publications (Minnesota Department of Children, Families and Learning 1997; Bohac, Linner, and Dunsworth 1996). The Table of Contents from the User's Manual is reproduced in Appendix C.

\subsection{DATA COLLECTION}

The first step in the data collection effort is to attach a run time data logger to the electrical controls of the heating system of each building being studied. This data logger records the times that the system is in operation. An ASAP analysis typically requires four weeks of preweatherization and four weeks of post-weatherization run time data during a period when the heating system is experiencing substantial usage. The run time data are downloaded from the data logger using SmartWare data retrieval software. Usually, this is done once at the end of the pre-weatherization period and again at the end of the post-weatherization period by bringing a portable computer to the job site and connecting the computer to the data logger. The pre- and post-weatherization electronic files are given separate names to avoid confusing them with each other. At the same time, the user keeps a paper record (referred to as a Data Logger Tracking Sheet) that shows - among other things - the building's identification number, fuel type, logger installation date, beginning and ending dates of weatherization work, the date the logger was removed, heating system input (or "firing") rate for the pre-and post-weatherization periods, and the names assigned to the pre- and post-weatherization computer files. 
INPUTS

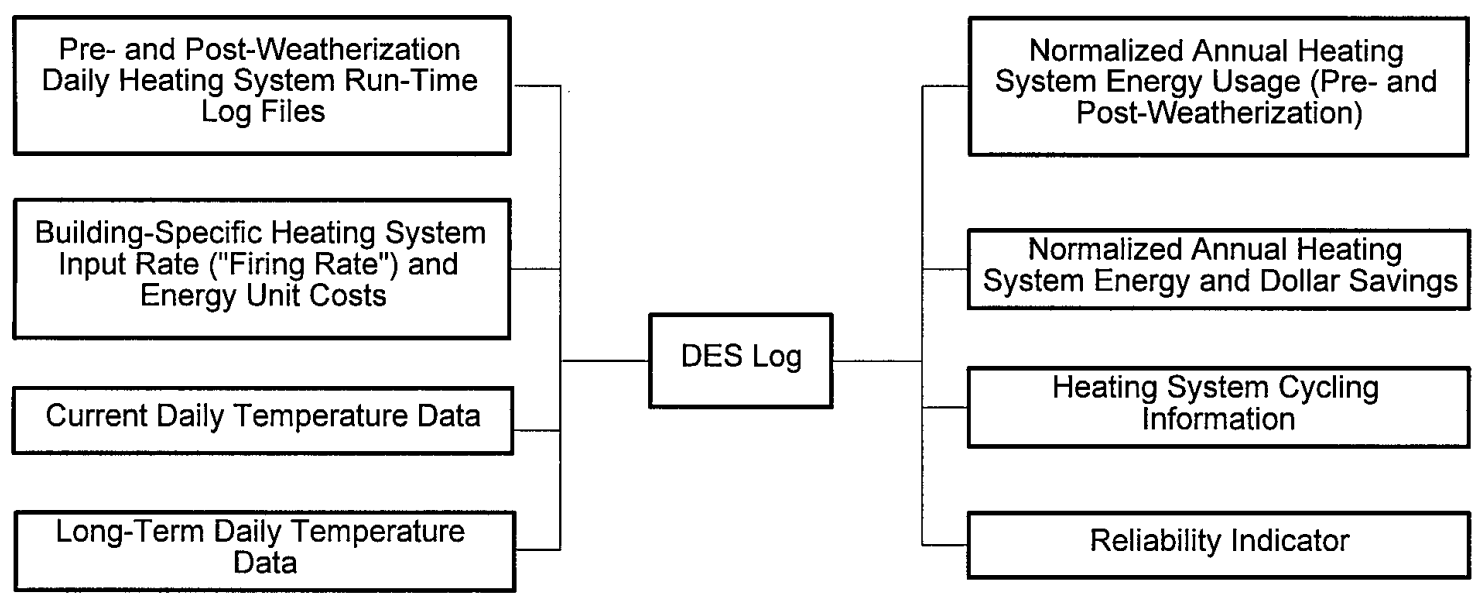

Source: Minnesota Office of Low-Income Energy Programs, 1998.

\section{Figure 6. Conceptual diagram showing major inputs and outputs associated with ASAP analysis.}

As mentioned earlier, the heating system input rate describes how much energy is consumed during each hour of heating system operation. It varies from one heating system to another and can also vary from the pre- to the post-weatherization period if the work done on the building in question includes heating system improvements or adjustments. For natural gas heating systems, the input rate can be calculated manually from the number of revolutions made by the meter in a given time period, or the DESLog software can compute this. For systems using other fuels, the calibration process is more difficult and should probably be done by a trained technician. However it is obtained, information on the firing rate is extremely important because it allows the transformation of heating system run times into fuel consumption numbers. Recording the unit cost of heating fuel also is important because this is an essential input for the calculation of dollar savings.

Current daily temperature data and long-term temperature files are the other essential inputs required for an ASAP analysis. The current weather data are necessary to identify how heating system energy use during the study period varies with outside temperature. Temperature data for a substantially longer period (30 years is recommended) is needed to convert pre- and post-weatherization energy use to weather-adjusted annual consumption so the two periods can be compared and the effects of the weatherization effort quantified. These temperature data should be collected for the major weather station that is closest to the weatherized structures, the same as in a PRISM analysis. 


\subsection{DATA QUALITY SCREENING}

As with any analysis, the numbers generated by ASAP are only as good as the data on which they are based. Accordingly, it makes sense to check the weather data for completeness and accuracy, as suggested in the section on PRISM. For each weatherized building, it is essential that the first and last dates of weatherization work are recorded and that run time files for the pre- and post-weatherization periods are clearly distinguished from each other so that weatherization-induced changes in energy consumption can be identified. Also, care should be taken to ensure that the name given to each run time data file matches the name assigned to the Data Logger Tracking Sheet for the same building. Finally, it is very important that heating system firing rates be determined correctly and that any difference in pre- and postweatherization rates is noted.

\subsection{ANALYSIS PROCEDURES}

While it would be possible for an evaluator to learn to use the ASAP system by carefully studying the Users' Manual, the program's developers recommend that users receive "hands-on training," and that seems like good advice. Because the system estimates annual energy usage through regression analysis and uses regression concepts in reporting results (e.g., slope, residuals), some prior knowledge of regression would be helpful (but not essential) for a wouldbe user. In addition, familiarity with windows-based software systems in general and Excel in particular would be advantageous.

The DESLog software-which is described in the Users' Manual as 'the centerpiece of the ASAP program" - translates the daily heating system run times recorded by the data logger into energy consumption records. It does this by multiplying the length of time each building's heating system operates during each day that records are kept by the same heating system's fuel input ("firing") rate. DESLog then produces building-specific regression equations that show how heating system energy consumption varies with outside temperature. The regression equation for each building studied can be expressed as a straight line that shows how energy use declines as outside temperature increases. The point at which a given structure uses no energy at all for space heating is referred to as that building's "reference temperature." Not only will this reference temperature vary from structure to structure, but it also typically varies for a single structure from the pre- to the post-weatherization period ${ }^{3}$.

For each structure that is examined, DESLog estimates weather-normalized annual energy consumption by entering long-term average weather data into the building-specific regression equations described above. Because the equations will differ for the pre- and postweatherization periods, the normalized annual consumption numbers calculated by DESLog will show the change in annual heating system energy use that is associated with building weatherization. Table 2, taken from the ASAP User's Manual, shows how a building's

\footnotetext{
${ }^{3}$ The outside temperature at which the heating system comes on will generally go down after weatherization as a result of a number of factors, such as reduced infiltration of outside air and less heat loss through windows and ceilings.
} 
Table 2. "Heating Models" Table Produced by DESLog Shows Changes in Reference Temperature and Heating Slope Following Weatherization

\begin{tabular}{cccc}
\hline Period & $\begin{array}{c}\text { Fuel Use } \\
(\text { Therms/year })\end{array}$ & $\begin{array}{c}\text { Reference } \\
\text { Temperature }(\mathrm{F})\end{array}$ & $\begin{array}{c}\text { Heating Slope } \\
(\text { Therms/F) }\end{array}$ \\
Pre & $707+/-43$ & $54.0+/-3.1$ & $0.091+/-0.005$ \\
Post & $418+/-17$ & $58.2+/-2.6$ & $0.066+/-0.005$ \\
\hline Change & $289+/-46$ & $5.8+/-4.1$ & $0.025+/-0.007$
\end{tabular}

Source: Minnesota Office of Low-Income Energy Programs, 1998.

reference temperature and heating slope can change from the pre- to the post-weatherization period and how that affects annual energy consumption.

DESLog uses its annual energy savings calculations and data on energy costs to compute annual dollar savings for each building. DESLog also does a summary table for the whole group of structures under study, showing average energy savings in absolute terms and as a percentage of pre-weatherization consumption (Table 3). Because the ASAP system studies only heating system energy use, savings are expressed as a percentage of pre-weatherization heating consumption. This can be contrasted to PRISM, which reports energy savings as a percentage of whole-house energy use for the fuel(s) studied.

The tables produced by ASAP that show annual energy and dollar savings also indicate whether or not these findings are considered to be reliable. Reliable numbers are those produced by regression equations that show a clear relationship between energy use and outside temperature, while unreliable numbers are associated with more questionable models that tend to produce inaccurate savings estimates. In addition to calculating energy savings, ASAP also provides information about heating system cycles. For each structure studied, tabular information is given on the number of heating cycles per day, the duration of the average daily cycle, and the percent of time that the heating system operated for each day of the study period. ASAP also produces charts showing how the number of heating cycles per day and average cycle length in each individual building varies with outside temperature, for both the pre- and postweatherization periods. This information can be useful to weatherization staff in their efforts to understand heating system performance.

\subsection{TIMING AND BUDGET}

To date, state-level ASAP based evaluations have been conducted only in-house so no cost estimates for a contractor study are available. In addition, ASAP should be conducted inhouse because its goals extend beyond simply obtaining a one-time energy savings estimate. In Minnesota, the collection of data on heating system run-times and firing rates has been incorporated into routine program procedures. Minnesota Weatherization Program managers estimate that in the start-up phase, when a good deal of trial-and-error learning was taking place, ASAP added about one additional day per house to the workload. Now that ASAP is fully 


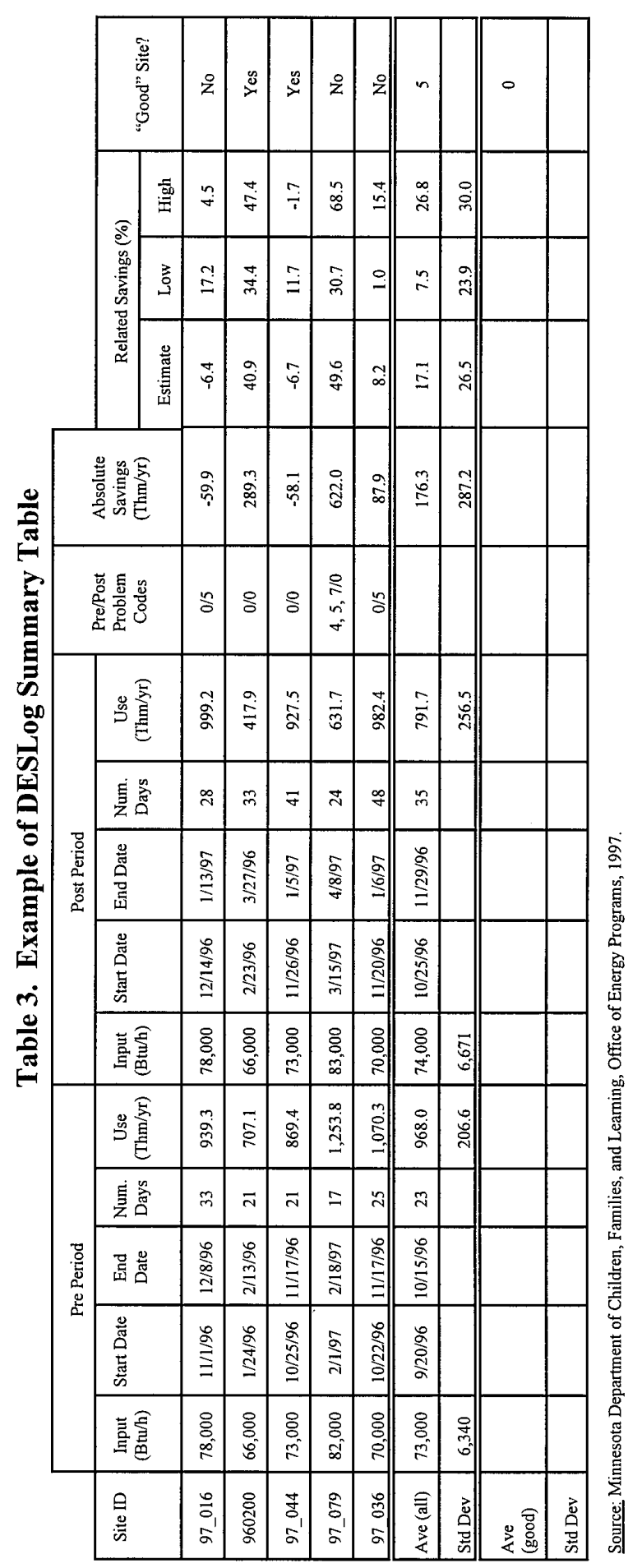


implemented, and everyone has gained experience in using it, the additional time per house is closer to two hours.

The major part of the effort in an ASAP study occurs in the data collection phase. Once the data are available, analysis costs are relatively small. In the average case, data collection might take about one month of FTE effort with a four month waiting time as the data loggers record run-times for a pre- and post-weatherization period in 50-100 houses. Data entry is automated in the ASAP system. Data analysis should take less than one month (FTE) in 50-100 houses.

Because ASAP requires only four to six weeks of pre- and post-weatherization run-time data, data collection efforts can be completed in one heating season in a cold or moderate climate region. In general, an ASAP study can be completed in less than one year after it begins.

Equipment costs to start an ASAP effort could range from $\$ 500$ for the software, a cable, and one CT logger to over $\$ 100,000$ if several hundred time-of-use CT loggers are purchased at the start. The necessary equipment and associated costs include:

$$
\begin{aligned}
& \text { Time-of-use software } \\
& \text { Interface cable } \\
& \text { Time-of-use CT logger (s) }
\end{aligned}
$$

$\$ 195.00$ (only one copy needed per agency)

$\$ 55.00$ (only one needed per agency)

$\$ 250.00$ (for each house monitored)

It is also useful to have a few laptop computers (old models are fine) so that data can be downloaded from the loggers in the field. It is, however, possible to retrieve the loggers and to download them back at a central location.

It is possible to start an ASAP monitoring effort with only a few CT loggers, which can be reused on as many homes during as many heating seasons as desired. To obtain an adequate sample size for a statewide study during the course of one heating season, however, it would be desirable to have several hundred loggers in operation on a representative sample of houses located throughout the state. Costs for purchasing 400 loggers at $\$ 250$ dollars apiece, however, would exceed $\$ 100,000$ at full price (perhaps a lower price for bulk purchases could be negotiated with Pacific Science and Technology). Another way to lower costs is to spread out data collection efforts over more than one heating season. For example, if enough meters were purchased to monitor 150 homes per heating season, then equipment costs would be about $\$ 38,000$, and a statewide study could be completed in two years.

Overall, an ASAP study is initially more costly than a PRISM study because of equipment purchases. ASAP also is much more demanding of in-house staff time because several new skills and procedures must be learned and incorporated into routine program operations. A PRISM study, in contrast, can be conducted by an independent contractor without much involvement on the part of Weatherization Program staff. PRISM studies are typically done on a stand-alone basis. Conducting another PRISM study several years later will require about the same level of effort, and cost about as much, as the first one did. An ASAP effort, on the other hand, requires a larger commitment of Program staff time and resources at start-up, but once an ASAP monitoring system is in place energy savings information can be produced on an ongoing basis without a great deal of additional expense. 


\title{
3.6 ASAP USER AND ORDERING INFORMATION
}

Although, it would be possible for an evaluator to learn to use the ASAP system by carefully studying the User's Manual, getting "hands-on training," as the program's developers recommend, seems like good advice. The Table of Contents of the User's Manual is reproduced in Appendix C. DESLog software, which the User's Manual refers to as "the centerpiece of the ASAP program," comes on a single diskette which can be used on Windows-based personal computers on which Microsoft Excel has been loaded. To order DESLog or get technical assistance regarding its use, contact:

\author{
Carol Raabe \\ Minnesota Office of Low-Income Energy Programs \\ 550 Cedar Street \\ St. Paul, MN 55101 \\ Phone: (612) 297-3406 \\ Fax: (612) 282-5907 \\ e-mail: carol.raabe@state.mn.us
}

Another key part of the ASAP system is the SmartLogger CT Logger, model TOU-CT, which is a portable electronic device for recording heating system run time. This device is manufactured by Pacific Science and Technology and can be ordered directly from the company. An information sheet from Pacific Science and Technology on its loggers and software is reproduced in Appendix C. To order, one should contact:

Pacific Science and Technology

64 NW Franklin Avenue

Bend, Oregon 97701

Phone: (800) 388-0770

Fax: (541) 385-9333

e-mail: info@pacscitech.com

SmartWare data retrieval software, which translates the data collected by the logger into electronic files, and the RS-232 interface, which allows information to be exchanged between the data logger and a laptop computer, are the other essential components of the ASAP system. Both of these items can be obtained from Pacific Science and Technology.

The ASAP User's Manual, which is available from Carol Raabe of the Minnesota Office of Low-Income Energy Programs (see address above), provides detailed instructions on how to identify heating system "firing rates" for gas, oil, and liquid propane gas systems. Users needing further instruction on this topic are referred to that document. The User's Manual also recommends that a data logger tracking sheet be filled out for all buildings that are studied, in order to ensure that all necessary data will be available when it is time to analyze weatherizationinduced savings. A sample tracking sheet for five weatherized houses is shown in Figure 7. 

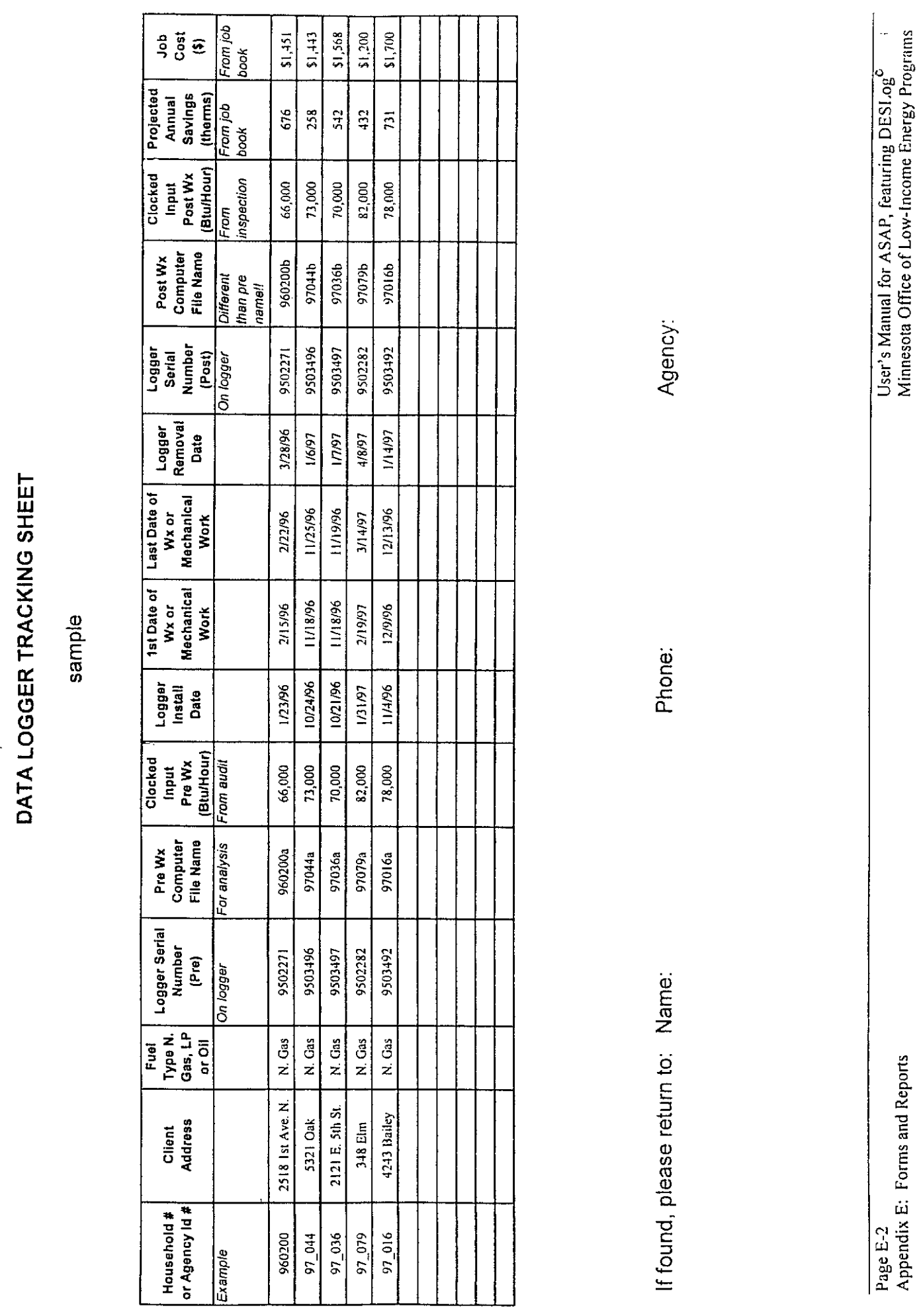

Figure 7. Sample data logger tracking sheet. 


\subsection{WEATHER DATA}

\subsection{DATA NEEDED FOR PRISM AND ASAP ANALYSES}

As discussed in Section 2.0 and Section 3.0, over ten years of daily temperature data are required for both PRISM and ASAP analyses. In both cases, temperature data are needed for the entire study period. This generally covers 12 months before and 12 months after weatherization for PRISM, and about four weeks pre- and post-weatherization for ASAP. Both systems also require that daily temperature records be collected for an extended period prior to weatherization so that average climatic conditions can be determined. For PRISM, a minimum of 12 years of daily temperature data is recommended, while ASAP's developers recommend that 30 years of data be obtained. These extended time frames can include the study period for which energy consumption data are collected. While only mean daily temperatures are required to run PRISM and ASAP analyses, it is common for a user to collect daily maximum and minimum temperatures and calculate daily means from those.

The daily temperature data described above should be collected for the primary weather station that is closest to the weatherized buildings. It may be necessary to gather data from multiple weather stations if the evaluation focuses on houses weatherized in more than one community. In that case, the dwelling units in each location should be matched with the nearest weather station. For a statewide evaluation, the number of weather stations needed will vary with the size of the state and the variety of its climate regions. The number of stations needed could be as low as two or three for a very small and homogeneous state or as high as 15 or 20 for a very large and climatologically varied state.

\subsection{OBTAINING WEATHER DATA}

The daily temperature data needed for a PRISM or ASAP analysis are available from the National Oceanic and Atmospheric Administration (NOAA). Specifically, the relevant data are contained in Series TD-3210 (Summary of the Day-First Order), which provides highly detailed information on primary weather stations throughout the country. Before ordering any data, the user should first identify the appropriate weather station(s) and ascertain whether complete data are available for the months and years in question. This can be done by calling up the website maintained by NOAA's National Climatic Data Center (NCDC), whose online address is http://www.ncdc.noaa.gov. One can search by state, county, city, or latitude and longitude to identify weather stations that have collected data for the required number of years. Stations for which TD-3210 data are available are indicated by the presence of a five digit WBAN number. The completeness of the data for any given station can be checked through the "Inventory" function. Once a station or stations are selected, the user should note the WBAN number because this information will be necessary when ordering weather data.

Using the NCDC website's "Online Store"-accessible at the same address given above - one can order the needed temperature data for any weather station in the country. To do a PRISM or ASAP analysis, a user will need daily maximum and minimum temperatures for the necessary number of years (see Sect. 4.1), making sure to include the dates for which energy 
consumption data are available. When ordering, it is important to remember that the information of interest is the TD summary of the day, that the data will be picked up online, and that the data should be "comma-delimited," showing station names. Users should also note that there is approximately a three month lag time before data become available so, for instance, someone ordering in January would only have access to data through September of the previous year. One can order up to 100 station-years of data in a single state for $\$ 70$. This amounts to a little more than 12 years of data for each of eight stations or more than 30 years of data for three stations. The cost for 101 to 1,000 station-years (which is sure to cover even the largest and most complex states) is \$200. At present, the calculation of station-years and the determination of charges are done separately for each state for which data are requested, so ordering 12 station-years of data in one state and 12 in another would cost $\$ 140(\$ 70+\$ 70)$, even though 24 station-years of data for a single state would only cost $\$ 70$. NOAA has plans to change this pricing scheme sometime in the future so that the tallying of station-years will occur without regard to state.

Additional information or assistance in ordering data from the NCDC website can be obtained by contacting NOAA staff by telephone at 828/271-4800. If ordering by computer is not feasible or convenient for some reason, one can order data over the telephone at the same number, but this method is considerably more expensive.

\subsection{CLEANING AND FORMATTING WEATHER DATA}

If temperature data for multiple weather stations are ordered from NOAA, they will come in a single file. Before an analysis can be performed in PRISM or ASAP, this combined file will have to be disaggregated into a set of separate temperature data files, one for each weather station. This can easily be done using word processing software, but it is important to note that the individual files must be saved as ASCII delimited files or else they will not be usable.

To be used in either a PRISM or ASAP analysis, temperature data should be put into the PRISM TPS format. The TPS format organizes weather data into monthly blocks, with each block listing the year, the month, the number of days in the month, and the mean temperature for each day. Each data point must be separated from the others by spaces and there cannot be any missing data (indicated either by extra spaces or the designation "-99999").

The temperature data provided by NOAA's online store are not in a format that can be used in PRISM or ASAP analyses. These data are also not in a format that can be directly converted into a TPS file. However, PRISM's designers have recently developed a routineNOAATOCOL - that can convert the NOAA files into columnar format. This routine will be provided to new users when they order PRISM software and can be requested by current PRISM users whose version does not contain it.

The columnar files described above can be converted into TPS files (necessary for both PRISM and ASAP analyses) using the PRISM Data Prep menu's "Column to TPS" routine. If one is using ASAP and does not have access to PRISM, the data can be converted to a TPS format by having a computer programmer write a conversion program to do this. 
Even in the best data sets, there are likely to be a few missing temperatures. These missing values must be replaced before the weather file can be used in a PRISM or ASAP analysis. In fact, this substitution should be performed when the file is in columnar form-saving the revised product as an ASCII file-before it is converted to TPS format. There are a number of different ways in which values for missing temperatures can be generated, including estimating maximum temperature from the non-missing minimum temperature for the same date (or vice versa), interpolating from non-missing values for the preceding and following dates, soliciting information for that site from the state climatologist, and substituting data from a nearby site. For an average weather station, it is likely to take two to four hours to do this data clean-up, but the time could be less for a very good data set and substantially longer for a set with lots of missing data. 


\subsection{SAMPLE SIZES FOR EVALUATIONS OF STATE WEATHERIZATION ASSISTANCE PROGRAMS}

Sample size is usually one of the most important determinants of the cost of a study. Up to a point, it is desirable to use the largest sample size you can afford to ensure the accuracy of the results. Although larger sample sizes produce more accurate results, the size of the sample you select does not have a direct linear relationship to the accuracy of the findings. There tends to be a ceiling effect where once a certain sample size is reached the rate of improvement in accuracy is diminished.

In a typical state (i.e., one that weatherizes between 1,000 and 5,000 homes per year and produces savings of between $15 \%$ and $30 \%$ of pre-weatherization consumption) sample sizes of more than 500 are unlikely to produce much increase in accuracy. As a rule of thumb, a sample size of about 350 usually will produce sufficiently accurate results (savings estimates that are within $10 \%$ of the mean at the $90 \%$ confidence level) in most states. As the size of the population of weatherized homes in a state increases, the required sample size increases too. These sample size increases are not, however, very large, nor are they proportional to the amount of increase in population size. In a state that weatherizes only 1,000 homes per year, for example, a sample size of 300 is sufficient. In a state that weatherizes 10,000 to 20,000 homes per year, the required sample size only increases to about 400 .

Sample size requirements for a given level of accuracy (expressed as a percentage of the mean) depend on the amount of variability in the measured savings. As a result, sample size requirements may vary simply because the amount of variability in the fuel savings that are observed differs. When houses are carefully screened, and dropped from the sample whenever confounding factors are present, the amount of variability across dwellings will be greatly reduced. With lower variability in the observed savings across dwellings, a smaller sample size can produce accurate results.

There are several important confounding factors that increase the variability in measured savings across dwellings. To the extent that these confounding factors can be eliminated by dropping the dwellings with such factors from the sample, a smaller sample size will be able to produce more accurate savings estimates. Three of the most important confounding factors include the use of supplemental heating sources, changes in occupancy, and changes in family composition. When dwellings that use supplementary heating sources such as electric or kerosene space heaters or wood stoves are included in a sample, there will be a great deal of variability in the savings observed in the primary heating fuel (e.g., natural gas). This occurs because of changes over time in how households use supplemental fuels. For example, after weatherization one household may stop using wood for heating, while another may increase the number of electric space heaters it uses. Another common source of high variability in observed savings is changes in occupancy (i.e., when a new family moves into the dwelling). In many cases, changes in the number of occupants and in their behavior may affect consumption patterns more than the Program treatment itself. Therefore, it is best to remove dwellings with occupancy changes from the study's sample, whenever possible. The third most common reason for high variability is changes in family composition. When a new baby is added to a family, or teenagers 
leave home, effects on energy use can be so large that they mask Program effects. Again, removing dwellings with such changes from the study's sample is a good way to reduce the amount of variation in the observed energy savings.

Although it is usually a good idea to remove dwellings with the confounding factors discussed above from a sample, there is sometimes a danger in carrying this strategy too far. In some states, for example, so many homes use supplemental fuels that removing all of them will produce a biased, unrepresentative sample of the homes receiving weatherization services. In Vermont, for instance, very high proportions of homes use wood as both a primary and secondary heating fuel. In Vermont, eliminating all of the homes that used wood, and other supplemental fuels, from the sample led to losses that were excessive. In particular, an initial sample of 543 units was reduced to a sample of only 55. Because newer, more energy-efficient homes were more likely to heat only with gas or electricity (and no wood), the evaluators in Vermont considered their study results to be biased. In other words, their sample of 55 homes was not representative of all of the homes receiving weatherization services in Vermont. As a result, the estimate of savings derived from this biased sample was probably lower than one based on a more representative sample would have been.

The calculation of the sample size one needs for an evaluation of a state's weatherization program depends on a number of inputs. The most important ones are:

- $\quad$ the magnitude of the mean energy savings

- the variability in the observed energy savings

- $\quad$ the desired precision of the estimate at a specified confidence level

Using the actual data from several recent state-level evaluations (See Appendix A for a list of these evaluations), Tables 4 and 5 illustrate how this process works. Table 4 contains the actual results from four state level evaluations conducted between 1996 and 1998. Table 4 shows that in studies A, B and D the mean percentage of energy savings and the standard deviation of the energy savings have nearly equal values. When the mean and the variability (as measured by the standard deviation of the sample data) have about the same value, even very small sample sizes produce reasonably useful results. If the sample sizes in studies A and B were increased, to the level shown in Table 5, then the results would be a good deal more precise. Table 5 shows that by increasing the sample size to 350, results in both evaluations A and B would have reached a precision that was within $10 \%$ of the mean. With the smaller sample sizes shown in Table 4 , in contrast, the precision of the estimate is only $38.5 \%$ of the mean for study A and $14.5 \%$ of the mean for study B. 
Studies C and D have very large sample sizes and, therefore, very precise estimates of savings, which are within $3.1 \%$ and $2.4 \%$ of the mean, respectively. Table 5 shows that for these studies the sample size could be decreased without producing an unacceptable impact on the precision of the estimates. In study D, a sample size of 400 would be needed to produce an estimate that was within $10 \%$ of the mean. In study C, a sample size of 590 would be needed to produce an estimate that was within $10 \%$ of the mean. The sample size in study $\mathrm{C}$ would need to be larger than in study $\mathrm{D}$ because the amount of variability in the observed savings is greater in study $\mathrm{C}$.

Table 4. Actual Sample Sizes and Results from Four Recent State-Level Evaluations

\begin{tabular}{|c|c|c|c|c|c|}
\hline Study & $\begin{array}{c}\text { Mean } \\
\text { Percentage } \\
\text { of Energy } \\
\text { Savings }\end{array}$ & $\begin{array}{c}\text { Standard } \\
\text { Deviation in } \\
\text { Percentage of } \\
\text { Savings }\end{array}$ & $\begin{array}{c}\text { Confidence } \\
\text { Interval* }\end{array}$ & $\begin{array}{c}\text { Precision of } \\
\text { the Estimate } \\
\text { as a } \\
\text { Percentage of } \\
\text { the Mean }\end{array}$ & $\begin{array}{c}\text { Actual } \\
\text { Sample Size } \\
\text { of the Study }\end{array}$ \\
\hline A & 26.0 & 28.8 & $16.0-36.0$ & 38.5 & 32 \\
\hline B & 12.4 & 10.9 & $9.3-15.5$ & 14.5 & 37 \\
\hline C & 23.2 & 34.3 & $22.1-24.4$ & 3.1 & 2209 \\
\hline D & 16.1 & 19.3 & $15.4-16.7$ & 2.4 & 2442 \\
\hline
\end{tabular}

*Study A is at the $95 \%$ confidence level. The other three are at the $90 \%$ confidence level.

Table 5. Illustration of How Increased Sample Size Produces Increased Precision and of How Decreased Sample Size Produces Decreased Precision

\begin{tabular}{|c|c|c|c|c|c|}
\hline Study & $\begin{array}{c}\text { Mean } \\
\text { Percentage } \\
\text { of Energy } \\
\text { Savings }\end{array}$ & $\begin{array}{c}\text { Standard } \\
\text { Deviation in } \\
\text { Percentage } \\
\text { of Savings }\end{array}$ & $\begin{array}{c}\text { Change in the } \\
\text { Confidence } \\
\text { Interval* }\end{array}$ & $\begin{array}{c}\text { Change in } \\
\text { Sample Size } \\
\text { of the Study }\end{array}$ & $\begin{array}{c}\text { Change in } \\
\text { Precision of } \\
\text { the Estimate } \\
\text { as a } \\
\text { Percentage } \\
\text { of the Mean }\end{array}$ \\
\hline A & 26.0 & 28.8 & $\begin{array}{c}\text { From 16.0-36.0 } \\
\text { to 23.5-28.5 }\end{array}$ & $\begin{array}{c}\text { From 32 to } \\
350\end{array}$ & $\begin{array}{c}\text { From } 38.5 \text { to } \\
9.7\end{array}$ \\
\hline B & 12.4 & 10.9 & $\begin{array}{c}\text { From 9.3-15.5 } \\
\text { To } 11.3-13.5\end{array}$ & $\begin{array}{c}\text { From 37 to } \\
350\end{array}$ & $\begin{array}{c}\text { From } 14.5 \text { to } \\
9.2\end{array}$ \\
\hline C & 23.2 & 34.3 & $\begin{array}{c}\text { From 22.1-24.4 } \\
\text { to 20.9-25.5 }\end{array}$ & $\begin{array}{c}\text { From } 2209 \\
\text { to 590 }\end{array}$ & $\begin{array}{c}\text { From 3.1 to } \\
10.0\end{array}$ \\
\hline D & 16.1 & 19.3 & $\begin{array}{c}\text { From 15.4-16.7 } \\
\text { to 14.5-17.7 }\end{array}$ & $\begin{array}{c}\text { From 2442 } \\
\text { to 400 }\end{array}$ & $\begin{array}{c}\text { From } 2.4 \text { to } \\
9.9\end{array}$ \\
\hline
\end{tabular}

*Study A is at the $95 \%$ confidence level. The other three are at the $90 \%$ confidence level. 


\subsection{CONFIDENCE INTERVALS}

When energy savings are calculated for a group of buildings using PRISM or ASAP, the analyst frequently wants to know the average amount of energy saved. The arithmetic mean is a simple and frequently-used measure of this, which is calculated by summing the savings for all the structures studied and dividing this by the number of buildings in the sample. However, sometimes the analyst wants to go further and use the savings realized by the sample in question to estimate savings for the entire population of homes weatherized by his or her program. This involves calculating the confidence interval of a mean.

Simply stated, the confidence interval of a mean tells us the probability that the mean value of a given variable for an entire population (which is unknown to us) will be within a certain distance of the sample mean (which we do know). This distance varies depending on the variability within the sample (as measured by the standard deviation for the variable in question), sample size (typically referred to as "n"), and the level of confidence we wish to have in the estimated population mean. For our purposes, the value we wish to estimate is the average amount of energy savings realized by all the buildings weatherized by a particular state weatherization program during a set time period.

If one knows the sample mean for energy savings, the standard deviation for that variable, and the size of the sample, it is fairly easy to estimate average savings for the entire population. First, it is necessary to establish the level of confidence that one wishes to have in the population estimate. Typically, an analyst will choose to be $.90(90 \%)$ or $.95(95 \%)$ sure of the estimated interval. Next, the standard error for energy savings is calculated by dividing the sample standard deviation by the square root of $\mathrm{n}$. Then, it is necessary to determine the " $\mathrm{t}$ value" for our desired level of significance and the appropriate degrees of freedom ( $\mathrm{df})^{4}$. Once that is done, the t-value is multiplied by the standard error. The number calculated in this manner should be added to the sample mean of energy savings to get the upper bound of the confidence interval for population energy savings, and subtracted from the sample mean to get the lower bound. The formula for calculating a confidence interval can be expressed as follows:

$$
\begin{aligned}
& \bar{y} \pm t_{\alpha / 2} \frac{s}{\sqrt{n}}, d f=n-1, \text { where } \\
& \bar{y}=\text { sample mean } \\
& \left.t_{\alpha / 2}=\text { the } \mathrm{t} \text {-value for the appropriate significance level (as explained in footnote } 4\right) \\
& \mathrm{s}=\text { standard deviation } \\
& \mathrm{n}=\text { sample size } \\
& \mathrm{df}=\text { degrees of freedom }
\end{aligned}
$$

The following example will illustrate how the above formula can be applied to calculate a confidence interval. We will assume that mean savings for our sample is 20 units, the standard

${ }^{4}$ A table of t-values can be found in the back of many statistical textbooks. The level of significance to use when reading the table is calculated by subtracting the desired confidence level from 1 and dividing this by 2 . Degrees of freedom is simply $\mathrm{n}-1$. 
deviation is 12 , and sample size is 100 . Therefore, the square root of $n$ is 10 . In this case, we wish to be $.95(95 \%)$ sure that the estimated population mean is within the specified distance of the sample mean. By dividing the standard deviation (12) by the square root of $n(10)$, we find that the standard error of our sample mean is 1.2. Turning to a table of t-values, we find that the $\mathrm{t}$-value for a significance level of .025 and df of 99 is approximately $1.99^{5}$. By multiplying 1.99 by the standard error of the mean (1.2), we get a value of 2.39 . This means that the $95 \%$ confidence interval of the population mean is 20 plus or minus 2.39 , or 17.61 to 22.39 . In other words, we can be $95 \%$ certain that average savings realized by the entire population of buildings weatherized by the program in question is between 17.61 and 22.39 units.

By following the steps described above, an analyst can go beyond the average savings calculated for his or her sample to estimate the probable range of mean energy savings for the entire population of interest at any given level of confidence.

${ }^{5}$ The significance level of .025 is calculated by subtracting .95 (our desired confidence level) from 1 and dividing this value (.05) by 2. Degrees of freedom is n (in this case, 100) minus 1, or 99. 


\subsection{DETERMINING THE COST EFFECTIVENESS OF WEATHERIZATION PROGRAMS}

The cost effectiveness of a weatherization program can be determined with a variety of approaches. Although a basic comparison of measured energy savings to the costs of achieving them is always involved, several other inputs are usually needed as well. Key assumptions include the expected lifetime of the retrofit measures, a discount rate that reflects the time value of money, and estimated fuel price escalation rates. Since there is significant uncertainty in these key assumptions, sensitivity analysis is often used to estimate a range of cost effectiveness under varying conditions.

The expected range of lifetimes for typical packages of weatherization retrofits is 15 to 20 years. This range is dependent, of course, on the overall lifetime of the dwelling and the mix of weatherization measures that are installed. Average expected lifetimes of 10, 15, and 20 years are an appropriate range for cost-effectiveness calculations.

To evaluate the cost effectiveness of a retrofit investment, one must weigh the future benefits against present costs. The weight given to benefits and costs in future time periods is determined by the discount rate. The higher the discount rate, the lower the future benefits and costs are valued compared with present benefits and costs. In other words, a discount rate reduces the nominal dollar value of these future savings and costs to their present values. A real discount rate is expressed in constant dollar values; that is, current dollar values are corrected for reduced purchasing power due to inflation. Unfortunately, there is no consensus on the question of the appropriate rate of discount for use in evaluating government energy projects. Determining the appropriate social rate of discount is a complex problem and continues to be the subject of controversy among professional economists.

When trying to arrive at the appropriate discount rate, it is important to note that benefits derived from weatherization retrofit investments are not taxable. Thus, after-tax rates of return for alternative investments should be used to determine appropriate discount rates. In addition, the alternative investments must be of the same time span as the lifetime of the weatherization retrofits.

A range of real discount rates has been used in previous evaluations of federal programs. For a sensitivity analysis we recommend discount rates of 3, 6, and $10 \%$. In addition, each state could use the current rate (net of inflation) at which the state borrows money as the discount rate.

Obtaining reasonable estimates of future fuel prices is a highly uncertain process. Yet, some assumption must be made to calculate most indicators of cost effectiveness. The American Gas Association (AGA) estimates real fuel price escalation rates for natural gas. The Energy Information Administration (EIA) publishes fuel price forecasts which are widely used in the evaluation of energy policies and programs. In addition, fuel price projections can be obtained from a state's fuel suppliers or public utility commission. Thus, a sensitivity analysis could include AGA, EIA, and local forecasts. 
To summarize, reasonable assumptions for estimating the cost effectiveness of weatherization retrofits include a range of retrofit lifetimes of 10,15 , and 20 years; discount rates of 3,6, and 10\%; and fuel price escalation rates based on governmental or fuel supplier forecasts (Table 6).

Table 6. Recommended Economic Parameters for Cost-effectiveness Calculations

\begin{tabular}{cccc}
\hline & $\begin{array}{c}\text { Retrofit } \\
\text { lifetime } \\
(\text { Yrs.) }\end{array}$ & $\begin{array}{c}\text { Discount } \\
\text { rate } \\
(\%)\end{array}$ & $\begin{array}{c}\text { Fuel price } \\
\text { Escalation factor } \\
(\%)\end{array}$ \\
\hline Range & $10,15,20$ & $\begin{array}{c}3,6,10, \text { and state } \\
\text { cost of money }\end{array}$ & $\begin{array}{c}\text { EIA, AGA, or local } \\
\text { supplier forecasts }\end{array}$
\end{tabular}

Once the key assumptions about retrofit lifetimes, discount rates, and future fuel price escalation rates are selected, a variety of cost-effectiveness indicators can be calculated with standard formulas (Fig. 8). The net present value (NPV), the cost of conserved energy (CEE), the internal rate of return (IRR), and the simple payback calculations are described below. The advantages, disadvantages, and underlying assumptions of each indicator are also briefly discussed.

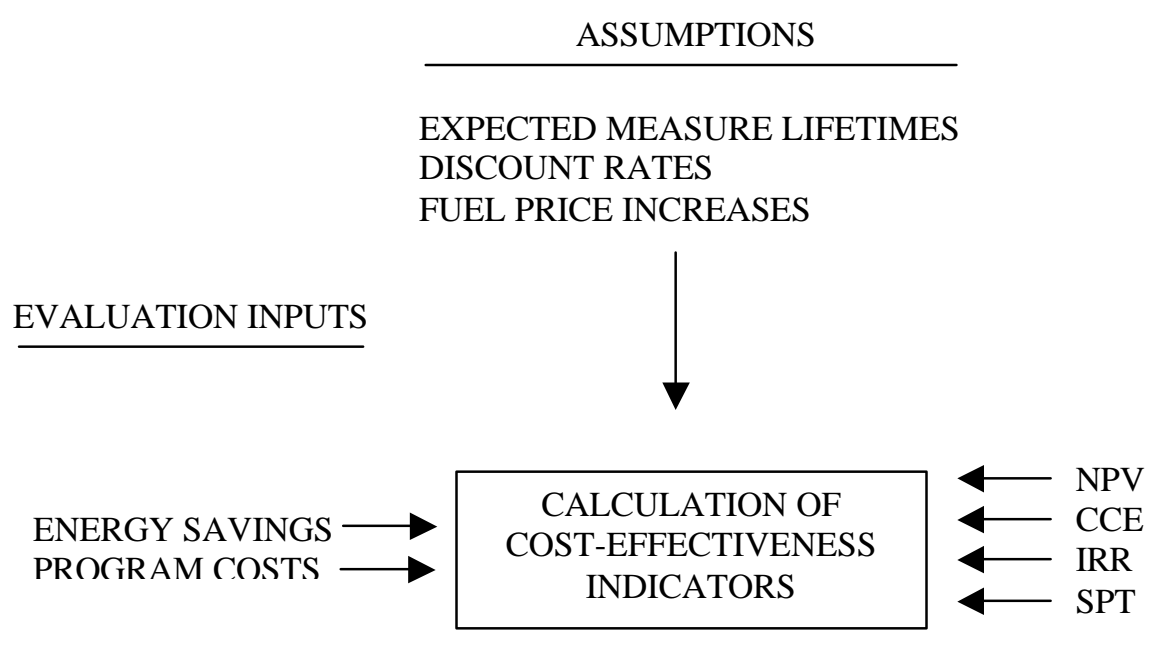

Figure 8. Cost-effectiveness analysis process. 


\subsection{NET PRESENT VALUE AND BENEFIT/COST RATIO}

Net present value (NPV) analysis calculates the difference between a retrofit measure's discounted benefits and costs. The energy saved and the cost of obtaining those savings are valued over the lifetime of the measure. An investment with a net benefit greater than zero is considered worthwhile. Measures with the highest NPV are the best investments. The general formula for NPV is:

$$
N P V=\sum_{j=1}^{n} \frac{S \bullet P_{j}-C_{j}}{(1+d)^{j}}
$$

where
$\mathrm{n}=$ lifetime of measure,
$\mathrm{S}=$ annual energy savings (equal to first-year savings),
$P_{j}=$ real energy price in year $\mathrm{j}$,
$\mathrm{C}_{\mathrm{j}}=$ annual cost of measure (in constant dollars). (Note: For the weatherization program, this will be the initial cost of the retrofit since maintenance costs are not being considered. Thus, the total cost will appear in year one and costs in subsequent years will be equal to zero),
$\mathrm{d}=$ real discount rate .

This formula sums the difference between the discounted benefits and costs each year over the lifetime of the measure. In practice, the present value of future energy savings is traded off against the total (first year or initial) investment cost for weatherization.

The calculation of the NPV of the lifetime benefits of weatherization (as described above) provides one of the necessary inputs for a benefit/cost ratio. The formula for calculating the NPV of the benefits is the same as Formula 1, except that the $\mathrm{C}_{\mathrm{j}}$ term is eliminated. The term $C_{j}$, which is the first year cost only, becomes the denominator for the benefit/cost ratio. Thus, the benefit/cost ratio is calculated by dividing the present value of the lifetime benefits of the retrofits by the first year costs of installing the measures.

\subsection{THREE PERSPECTIVES}

Three perspectives are commonly used for calculating benefit/cost ratios for the weatherization program (Figure 9). 


\begin{tabular}{|c|c|c|}
\hline $\begin{array}{l}\text { Benefit/Cost } \\
\text { Perspective }\end{array}$ & $\begin{array}{l}\text { Benefits } \\
\text { Included }\end{array}$ & $\begin{array}{c}\text { Costs } \\
\text { Included }\end{array}$ \\
\hline Installation & $\begin{array}{l}\text { Energy } \\
\text { Savings } \\
\text { Only }\end{array}$ & $\begin{array}{l}\text { On-Site } \\
\text { Installation } \\
\text { Costs }\end{array}$ \\
\hline Program & $\begin{array}{l}\text { Energy } \\
\text { Savings } \\
\text { Only }\end{array}$ & All Costs \\
\hline Societal & $\begin{array}{c}\text { Both Energy } \\
\text { and Nonenergy } \\
\text { Benefits }\end{array}$ & All Costs \\
\hline
\end{tabular}

Figure 9. Three perspectives used to calculate cost effectiveness.

These perspectives are the:

- Installation perspective, which includes only energy savings benefits and on-site installation costs (materials and labor).

- $\quad$ Program perspective, which includes only energy savings benefits, but compares these benefits to all costs (i.e. installation costs plus management and overhead costs).

- $\quad$ Societal perspective, which includes the most complete set of costs and benefits. In this perspective, the sum of energy and nonenergy benefits is compared to all costs.

Each of these perspectives is valuable for different purposes. The installation perspective is useful for comparing a study's results to many previous evaluations of weatherization programs because this is the most frequently used perspective. The program perspective is the most conservative and easily defended estimate of cost effectiveness. If a program is cost effective from this perspective, it will be from all of the others too. The societal perspective is best for valuing a more complete set of program benefits and for comparisons with alternate uses of government funds. 


\subsection{COST OF CONSERVED ENERGY}

The cost of conserved energy (CCE) is found by dividing the annualized cost of the retrofit by the annual energy savings due to the investment (Formula 2). The CCE is particularly useful if one wants to compare conservation investments to purchases of fuel. CCE can be expressed as

$$
C C E=\frac{I}{S}\left[\frac{d}{1-(1+d)^{-n}}\right],
$$

where

$\mathrm{I}=$ total investment,

$\mathrm{S}=$ annual energy savings (equal to first-year savings),

$\mathrm{d}=$ real discount rate,

$\mathrm{n}=$ lifetime of measure.

CCE provides an effective means of rank-ordering conservation investments by cost effectiveness. Calculating the cost per unit of energy saved makes direct comparison to supply costs per unit of energy produced possible. Thus, for policy purposes, a CCE approach clarifies the issue of where federal energy dollars can be most effectively spent. Another advantage of the CCE indicator is that it allows for comparisons across programs that are in areas with widely varying fuel costs, because fuel cost is not part of the CCE formula.

\subsection{INTERNAL RATE OF RETURN}

The internal rate of return (IRR) can be used to find the economic return on an investment (Formula 3). Typically, IRR is solved through an iterative process that finds the interest rate for which the net value of the investment is equal or close to zero. The IRR is then compared to the investor's minimum acceptable rate of return to determine the quality of the investment. The IRR requires an estimate of future energy prices and a measure's expected lifetime but no specification of a discount rate. The internal rate of return is $i$ in the following equation:

$$
I(1-T I)=\sum_{j=1}^{n} \frac{S \bullet P_{j}}{(1+i)^{j}},
$$


where

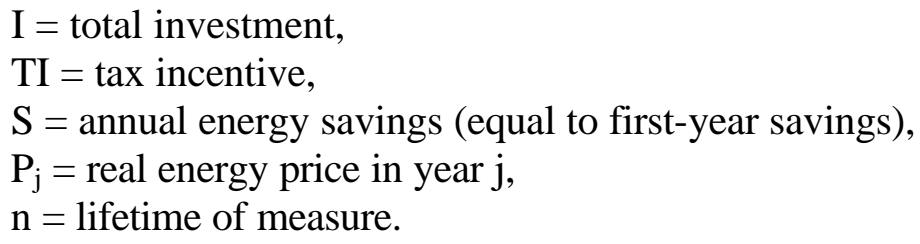

This indicator is capable of reflecting the relative economic efficiencies of alternative investments and can be used to rank competing projects. Thus, it would probably be most useful to individuals making choices among competing investments. In addition, it can be compared to the rate at which money can be borrowed. The IRR has the disadvantage of being cumbersome to calculate.

\subsection{SIMPLE PAYBACK}

Simple payback time (SPT) is a measure of the length of time required for the cumulative savings from an investment to pay back the initial cost (Formula 4).

It can be expressed as

$$
S P T=\frac{I}{S \bullet P}
$$

where

$$
\begin{aligned}
& \mathrm{I}=\text { initial investment, } \\
& \mathrm{S}=\text { annual energy savings (equal to first-year savings), } \\
& \mathrm{P}=\text { local energy price. }
\end{aligned}
$$

Although SPT is easily understood and widely used, it neglects temporal changes in energy prices, the expected life of the investment, differential operating and maintenance costs, and the time value of money. The indicator's failure to account for key economic variables means that simple payback often gives biased and misleading investment signals. For example, SPT ignores any changes in conditions after the payback has been achieved. Two retrofit measures with the same payback may have very different physical lifetimes; hence, one measure produces additional energy and dollar savings while the other requires replacement.

Because of the purposes and limitations of IRR and SPT calculations, we believe that NPV and CCE calculations are the most suitable for determining the cost effectiveness of weatherization programs. Once energy savings data, cost data, and key assumptions are available, however, any of the calculations can be done at little additional expense. In the process of determining cost effectiveness (Figure 8), a great deal more effort is required for determining inputs and assumptions than is required for doing the calculations. Thus, if one wishes to compare the results of several indicators, there is no reason not to do so. 


\subsection{REFERENCES}

Berry, Linda G., Marilyn A. Brown, and Lawrence F. Kinney. 1997. Progress Report for the National Weatherization Assistance Program, ORNL/CON-450, Oak Ridge National Laboratory, Oak Ridge, Tenn.

Berry, Linda G. 1997. State-Level Evaluation of the Weatherization Assistance Program in 1990-1996: A Metaevaluation That Estimates National Savings, ORNL/CON-435, Oak Ridge National Laboratory. Oak Ridge, Tenn.

Berry, Linda G., and Marilyn A. Brown. 1994. Patterns of Impact in the Weatherization Assistance Program: A Closer Look, ORNL/CON-331, Oak Ridge National Laboratory. Oak Ridge, Tenn.

Bohac, D., K. Linner, and T. Dunsworth, 1996, "Weatherization Program Short-Term Evaluation Methods," 1996 ACEEE Summer Study, Vol. 3, pp. 3.23-3.31.

Brown, Marilyn A., Linda G. Berry, Richard A. Balzer, and Ellen Faby. 1993a. National Impacts of the Weatherization Assistance Program in Single-Family and Small Multifamily Dwellings, ORNL/CON-326, Oak Ridge National Laboratory. Oak Ridge, Tenn.

Brown, Marilyn A., Linda G. Berry, Laurence F. Kinney. 1994. Weatherization Works: Final Report of the National Weatherization Evaluation, ORNL/CON-395, Oak Ridge National Laboratory. Oak Ridge, Tenn.

Brown, Marilyn A., Linda G. Berry, Laurence F. Kinney, James O. Kolb, Thomas C. Wilson, and Dennis L. White. 1993b. Keys To Success: Ten Case Studies of Effective Weatherization Programs, ORNL/CON-328, Oak Ridge National Laboratory. Oak Ridge, Tenn.

Eisenberg, Joel F., Eugene Michels, David Carroll, and Nancy Berdux. 1994. The Scope of the Weatherization Assistance Program: Profile of the Population in Need, ORNL/SUB/92SK904/V2, Oak Ridge National Laboratory, Oak Ridge, Tenn.

Fels, M.F., K. Kissock, M.A. Marean, and C. Reynolds, 1995, PRISM (Advanced Version 1.0) Users' Guide, Center for Energy and Environmental Studies, Princeton University, Princeton, NJ, January.

Fels, M.F., J.K. Kissock, and M.A. Marean, 1994, "Model Selection Guidelines for PRISM (or: Now that HC PRISM is Coming, How Will I Know When to Use It?)" 1994 ACEEE Summer Study, Vol. 8, pp. 8.49-8.61.

Fels, M.F., and C.L. Reynolds, 1990, "Now That I've Run PRISM, What Do I Do with the Results?" Home Energy, September/October, pp. 27-34. 
Fels, M.F., 1986, “PRISM: An Introduction,” Energy and Buildings, Vol. 9, Numbers 1 and 2, February/May, pp. 5-18.

Goldberg, M.L., 1986, "A Midwest Low-income Weatherization Program Seen through PRISM," Energy and Buildings, Vol. 9, Numbers 1 and 2, February/May, pp. 37-44.

Hirst, E., 1986, "Electricity Savings One, Two, and Three Years After Participation in the BPA Residential Weatherization Pilot Program," Energy and Buildings, Vol. 9, Numbers 1 and 2, February/May, pp. 45-53.

MacDonald, J. Michael. 1993. Description of the Weatherization Assistance Program in Larger Multifamily Buildings for Program Year 1989. ORNL/CON-329, Oak Ridge National Laboratory, Oak Ridge, Tenn.

Mihlmester, Phillip E., Wallace C. Koehler, Jr., Mark A. Beyer, Marilyn A. Brown, and Darrell A. Beschen, Jr. 1992. Characterization of the Weatherization Assistance Program Network, ORNL/CON-324, Oak Ridge National Laboratory, Oak Ridge, Tenn.

Minnesota Department of Children, Families and Learning, Office of Energy Programs, 1997, Data Logger Plan Fiscal Year 1998, September.

Minnesota Office of Low-Income Energy Programs, 1998, User's Manual for ASAP, Featuring DESLog

Power, Meg, Joel F. Eisenberg, Eugene Michels, Marjorie J. Witherspoon, and Marilyn A. Brown. 1993. Scope of the Weatherization Assistance Program: The Weatherized Population and the Resource Base, ORNL/CON-325, Oak Ridge National Laboratory, Oak Ridge, Tenn.

Schweitzer, Martin and Linda Berry. 1999. Metaevaluation of National Weatherization Assistance Program Based on State Studies, 1996-1998, ORNL/CON-467, Oak Ridge National Laboratory, Oak Ridge, Tenn.

Ternes, Mark P., and William P. Levins. 1993. Impacts of the Weatherization Assistance Program in Fuel-Oil Heated Houses, ORNL/CON-327, Oak Ridge National Laboratory, Oak Ridge, Tenn.

Tonn, Bruce and Dennis White. 1986. Residential Wood-Use in the Pacific Northwest: 19791985, ORNL/CON-216, Oak Ridge National Laboratory, Oak Ridge, Tenn. 


\section{APPENDIX A}

\section{STATE EVALUATIONS USED IN 1996 METAEVALUATION}

Columbia Gas of Ohio, 1993. An Analysis of the Columbia Gas 1990-91 Ohio Warm Choice Program, prepared by A\&C Enercom, Inc., for Columbia Gas of Ohio.

Columbia Gas of Ohio, 1995. An Administrative Report on the Columbia Gas 1993-94 Warm Choice Program, prepared by A\&C Enercom, Inc., for Columbia Gas of Ohio.

Indiana CAP Directors' Association, Inc., 1992. Energy Savings in Homes Weatherized by Six Indiana Weatherization Agencies: An Evaluation of Measured Savings and Cost Effectiveness, prepared by William H. Hill, Center for Energy Research/Education/Service. Ball State University, Muncie, Indiana.

The Statewide Low-income Collaborative Evaluation (SLICE) of Iowa., 1994. An Evaluation of Iowa's Low-Income Weatherization Efforts, prepared by Wisconsin Energy Conservation Corporation, August 8.

New York State Energy, Research and Development Authority and New York Department of State, 1993. Instrumented Audits Technology Transfer Project, prepared by Svnertech Systems Corporation. Energy Authority Report 94-6.

North Dakota Weatherization Assistance Program, 1993. Evaluation of North Dakota's Weatherization Assistance Program: Report of Findings, prepared by Conservation Management Corporation, Bethesda, Maryland, and by Tighe Energy Consultants, Arlington, Virginia.

Public Service Company of Colorado, 1995. Performance Measurement of the Energy Savings Partners Program, prepared by the Program Evaluation Unit of Public Service Company of Colorado.

Sharp, Terry, 1994. The North Carolina Field Test: Field Performance of the Preliminary Version of an Advanced Weatherization Audit for the Department of Energy's Weatherization Assistance Program. ORNLICON-62, Oak Ridge National Laboratory, Oak, Ridge, Tennessee.

Sharp, Terry, 1993. "Advancing, Weatherization Performance: Measured Results from the North Carolina Field Test of an Advanced Measure Selection Technique," Proceedings of the 1993 Energy Program Evaluation Conference, Chicago. pp.711-71.

Texas Department of Housing, 1995. Final Report.- Advanced PRISM Analysis of 182 Residential Houses in Texas that Underwent Energy Retrofits, prepared by J. Wang, D. Claridge, J. Haberl, and T. Reddy, Energy Systems Laboratory, Texas A\&M University. 
Vermont State Office of Economic Opportunity, Weatherization Assistance Program, 1993. Impact Evaluation of the 1992-1993 Vermont Weatherization Assistance Program, prepared by Vermont Energy Investment Corporation.

Vermont State Office of Economic Opportunity, Weatherization Assistance Program, 1995. Impact Evaluation of the 1993-1994 Vermont Weatherization Assistance Program, prepared by Vermont Energy Investment Corporation. 


\section{METAEVALUTION}

Dalhoff and Associates, 1996. An Evaluation of the 1995 Iowa Low-Income Collaborative Weatherization Program, Verona, Wisconsin, November 5.

Dalhoff and Associates, 1997. Report on Impacts and Costs of the 1996 Iowa Low-Income Weatherization Program, Verona, Wisconsin, May 31.

Hendron, Robert, 1997. Analysis of Energy Savings Achieved by DCEO Weatherization Program, 1997. DOE Philadelphia Regional Support Office, December 31.

Reed, John H., Nicholas P. Hall, Andrew Oh, Paul Hoover, and John Oh, 1997. An Impact Evaluation of Vermont's Weatherization Assistance Program, Arlington, Virginia, December.

RLW Analytics, Inc., 1998. Public Service Company of Colorado and Colorado Office of Energy Conservation Evaluation of the Energy Savings Partners Program Impact Evaluation, DRAFT, Clark Lake, Michigan, April 15.

Shen, Lester S., David L. Bohac, Karen L. Linner, and Timothy S. Dunsworth, 1996.

Development of Production-Based Tools and Protocols for Weatherization Program Assessment, Final Report for Minnesota Department of Economic Security, Minneapolis, Minnesota, September 10.

Wang, Young-Doo, Joseph K. Berko, Jr., Kyung-Jin Boo, John Byrne and Deirdre Rockwell Lord, 1996. Impacts of the Delaware Low-Income Weatherization Program on Energy and Economic Savings Newark, Delaware, December. 
A-4 


\section{APPENDIX B \\ Table of Contents from the \\ PRISM User's Manual}

Acknowledgements

Introduction 1

Getting Started

Chapter 1. Summary of Advanced Features of PRISM ................................................ I-1

Selection of Temperature and Meter Files............................................................... I-1

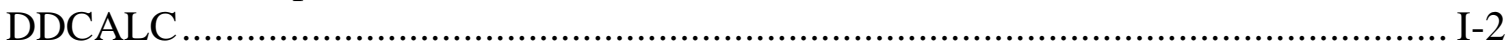

Choice of PRISM Models................................................................................... I-3

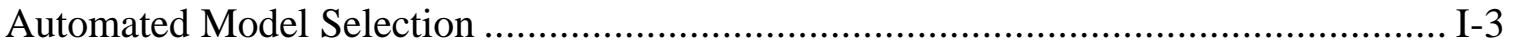

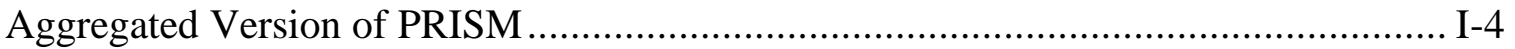

Choice of Set Of Buildings ............................................................................. I-4

Choice of PRISM Output Files ........................................................................ I-4

Choice of PRISM Options ................................................................................ I-5

Comparison of Models for Single Building............................................................ I-6

After the PRISM Run: Summary of Plots ......................................................... I-6

Identification and Correction of Estimated Readings ........................................ I-7

Outlier Detection and Use of Robust PRISM ..................................................... I-8

Change of Reliability Criteria ....................................................................... I-8

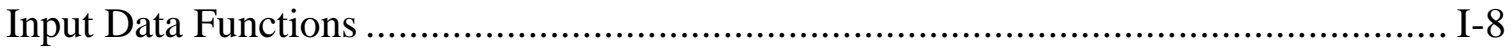

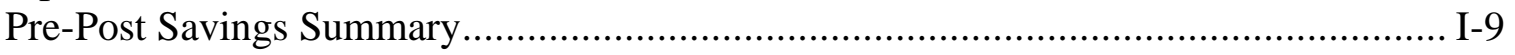

Chapter 2. Installing PRISM ....................................................................... I-11

Hardware and Software Requirements ........................................................ I-11

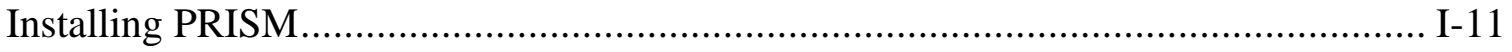

Chapter 3. Getting Set Up ................................................................................ I-15

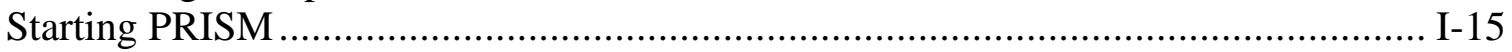

The PRISM Work Screen .................................................................................. I-15

Chapter 4. A Short Tutorial ................................................................................... I-19

Opening Temperature Files and Creating Normalization Files .............................. I-19

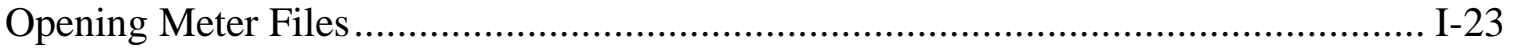

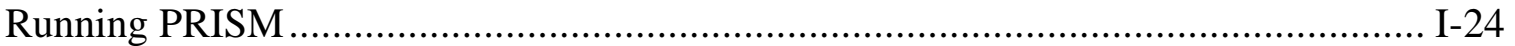

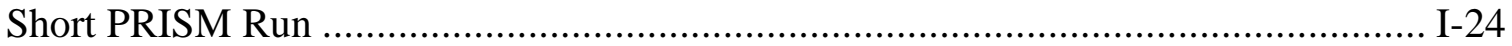

Longer PRISM Run (to view options) ....................................................... I-25

Accessing PRISM Output .............................................................................. I-31

Viewing/Using the Summary Plots from a PRISM Run ..................................... I-31

Viewing PRISM Output Files ................................................................ I-34 
Getting Started (cont'd)

Using the .LOG file to Review the PRISM Run .................................................... I-36

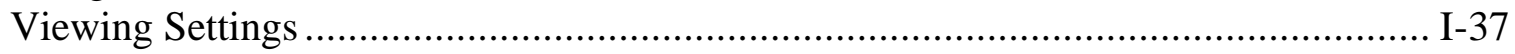

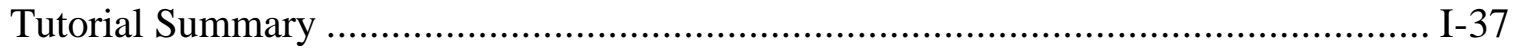

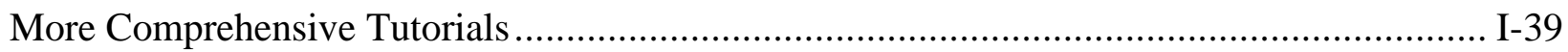

Tutorial in Automated Model Selection ................................................................. I-39

Tutorial in Estimated Reading Correction .............................................................. I-42

Tutorial in Aggregated PRISM ...................................................................... I-45

Tutorial in Savings Summary ………............................................................... I-46

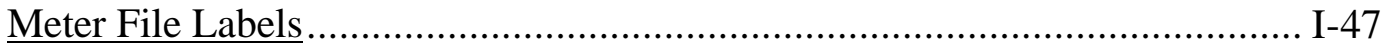

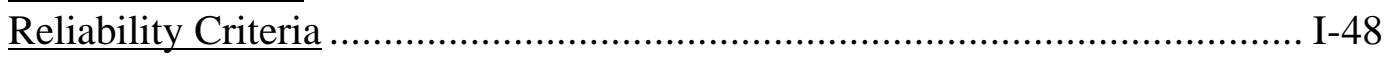

Viewing Normalized Savings...................................................................... I-49

Viewing Savings Histogram...................................................................... I-50

Viewing Percent Savings Histogram ....................................................... I-50

Viewing Savings Summary Table ……….................................................... I-51

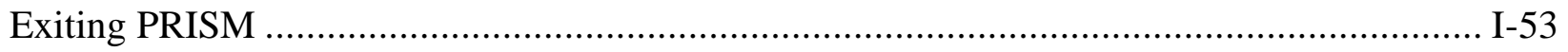




\section{APPENDIX C}

Table of Contents from the

ASAP User's Manual

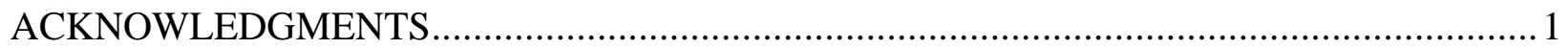

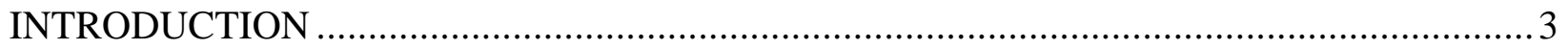

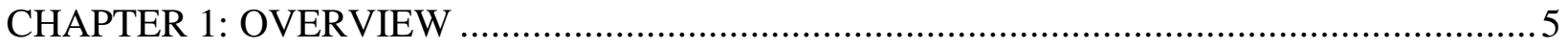

CHAPTER 2: MATERIALS, EQUIPMENT AND SUPPLIES …...................................... 7

SECTION 1: DATA LOGGER ................................................................................. 7

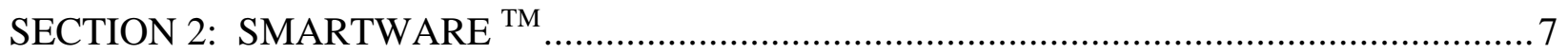

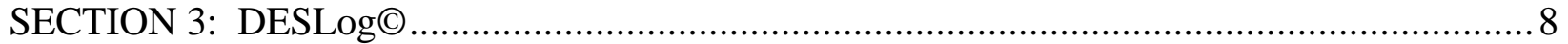

SECTION 4: LAPTOP COMPUTER ................................................................... 10

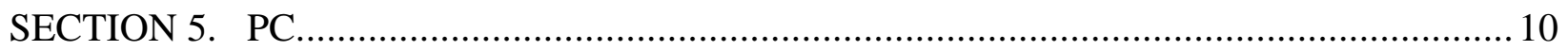

SECTION 6. EXCEL ............................................................................................ 10

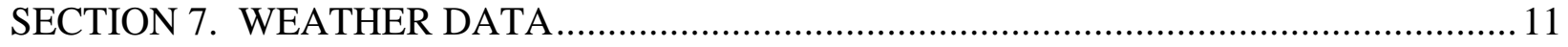

CHAPTER 3: SETTING UP AND USING EQUIPMENT .............................................. 13

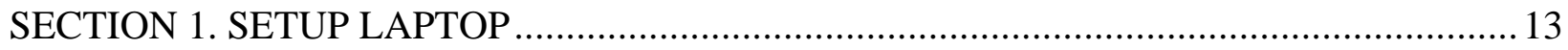

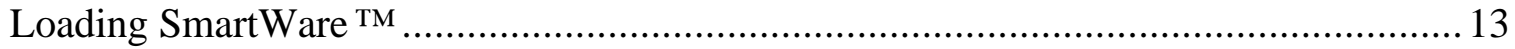

Setting the Time and Date ................................................................................. 13

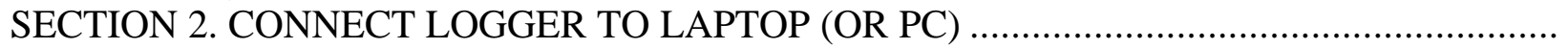

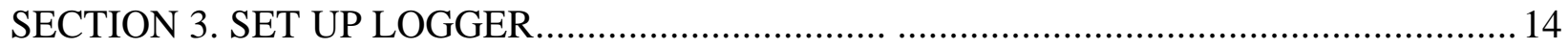

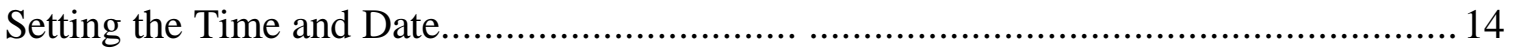

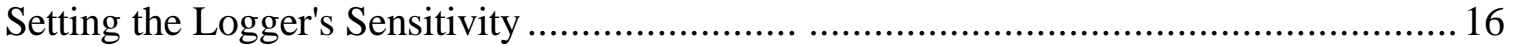

SECTION 4. SET UP SMARTWARE TM …............................................................. 16

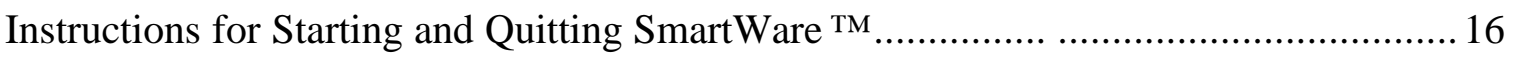

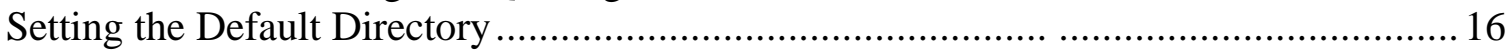

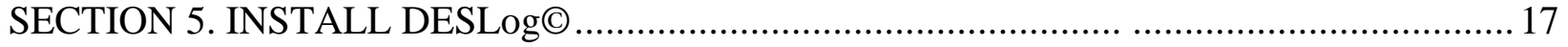

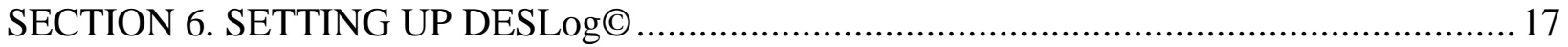

Create a New Workbook .................................................................................. 17

Select a Weather Station................................................................................ 19

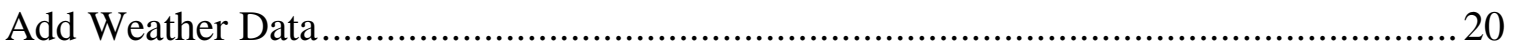

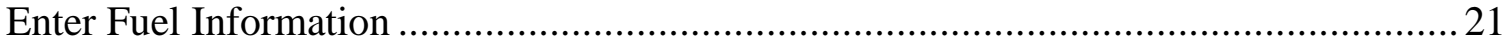

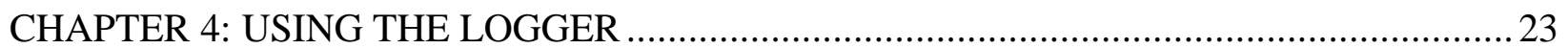

SECTION 1. SELECT THE HOUSE FOR ASSESSMENT ..........................................2 23

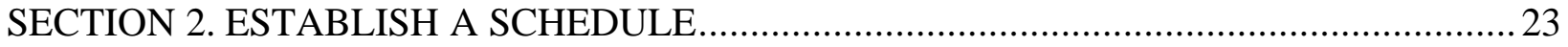

SECTION 3. INSTALL THE DATA LOGGER ................................................................ 24 


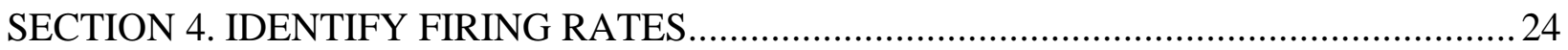

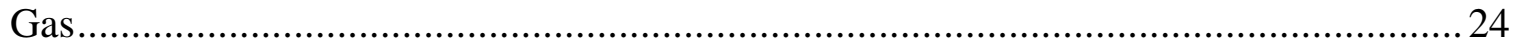

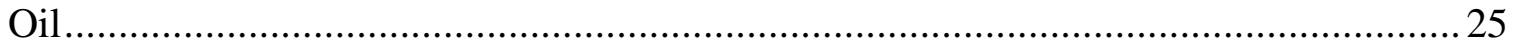

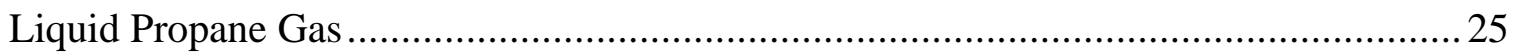

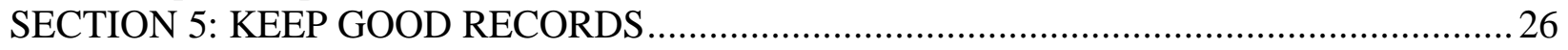

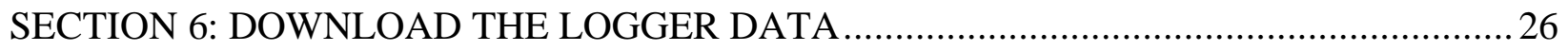

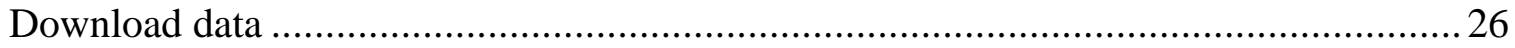

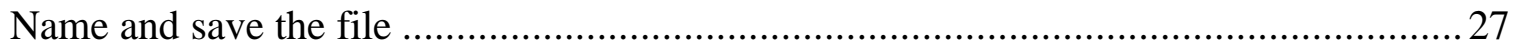

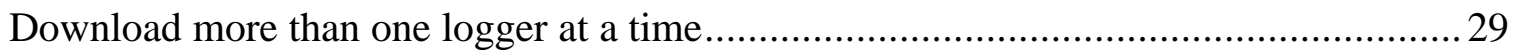

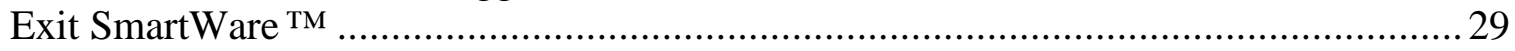

Check that you have downloaded the logger data correctly .........................................2 29

Monitor your data NOW........................................................................................ 30

Additional Steps for Downloading Post Data................................................................. 31

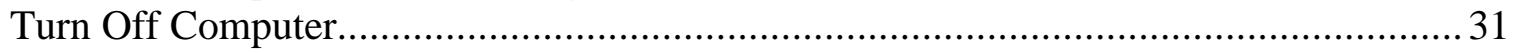

CHAPTER 5: PROCESSING LOGGER DATA WITH DESLOG@ ......................................... 33

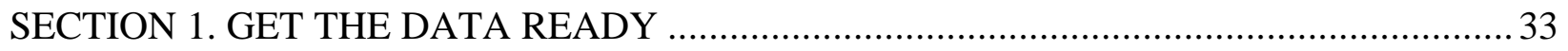

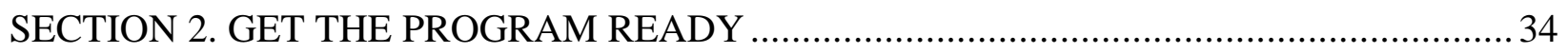

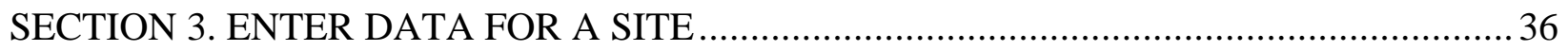

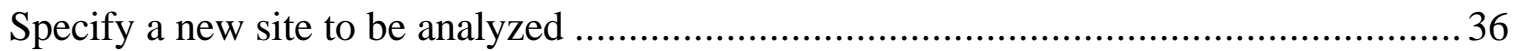

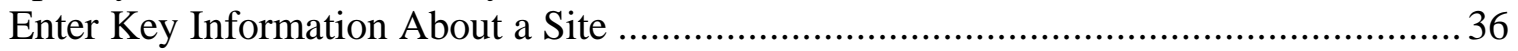

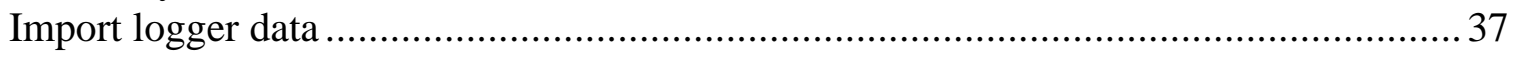

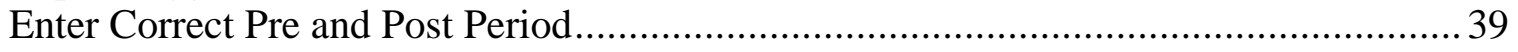

Specify the type of fuel used...................................................................................... 40

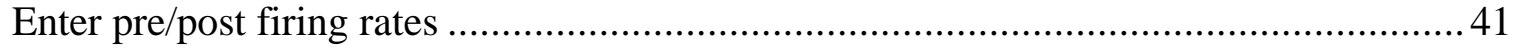

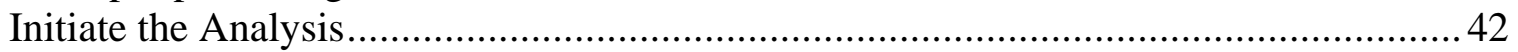

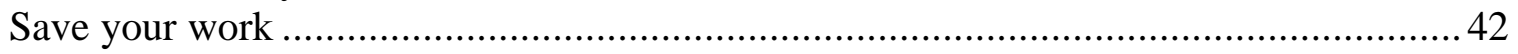

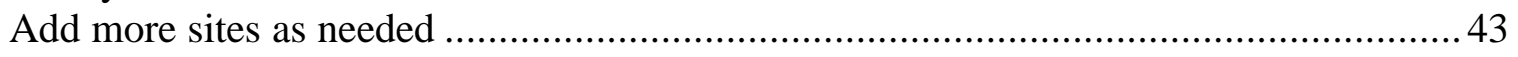

Modify results of an existing site ............................................................................. 43

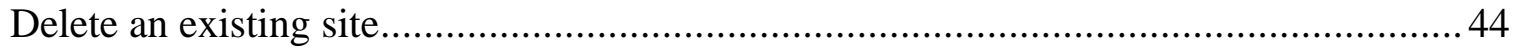

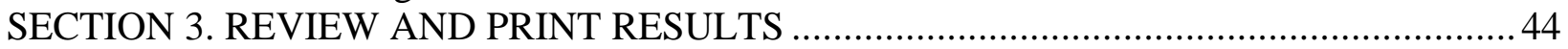

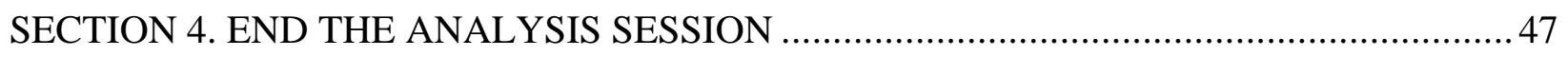

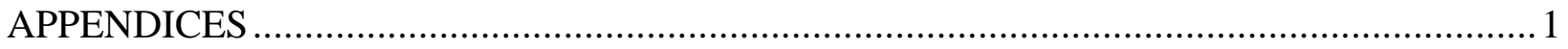

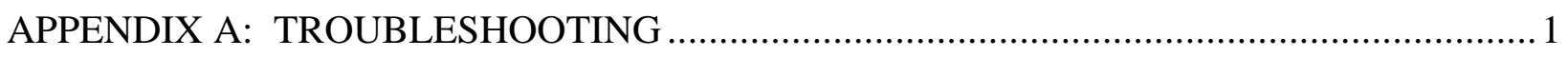

The basics 1

Will the DESLog $\odot$ program open correctly? .......................................................... 1

Does the program correctly analyze a site? ............................................................ 1

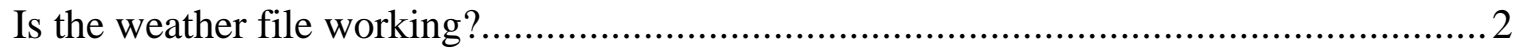

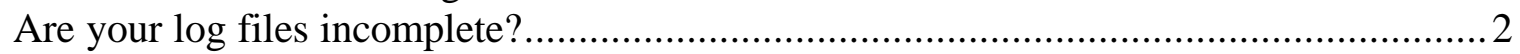

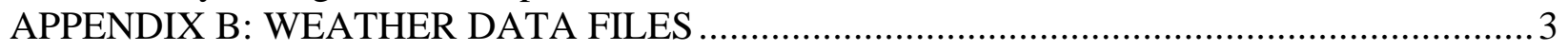

APPENDIX C: TECHNICAL BACKGROUND MATERIAL ……....................................... 7

Considerations for Heating System Fuel Type ………................................................

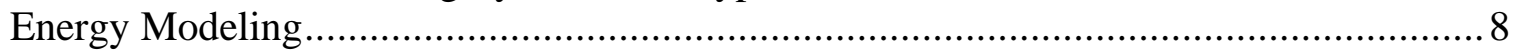




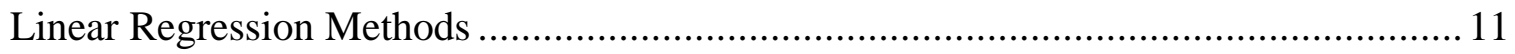

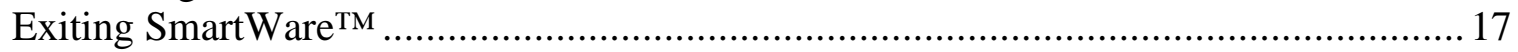

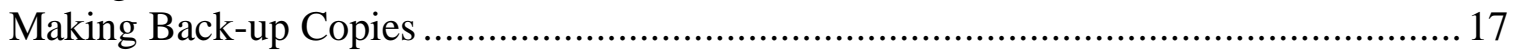

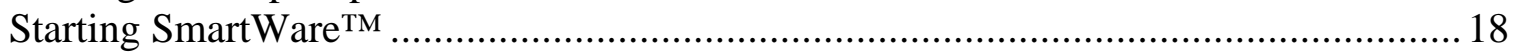

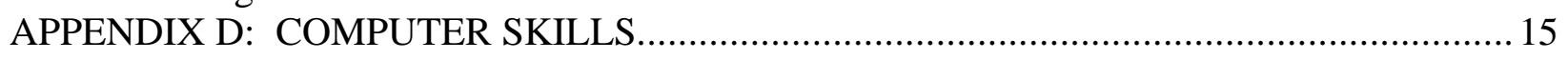

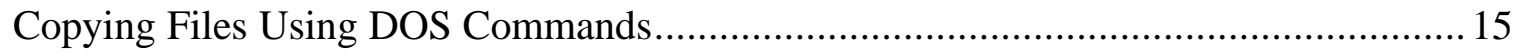

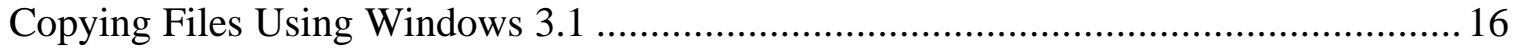

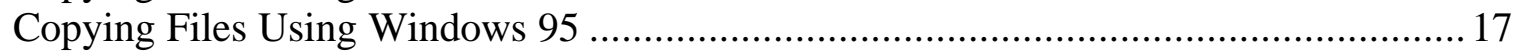

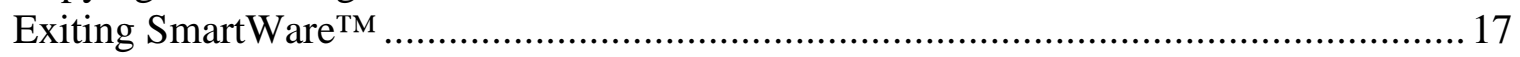

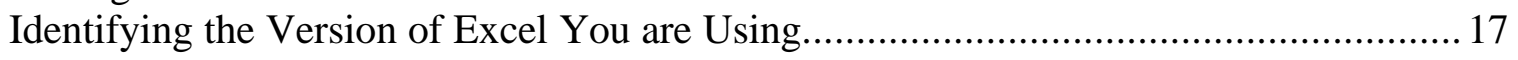

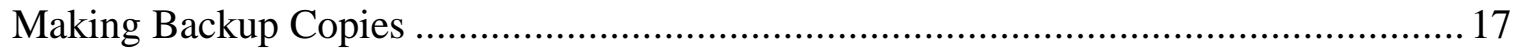

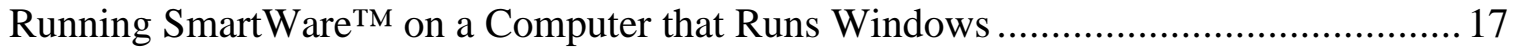

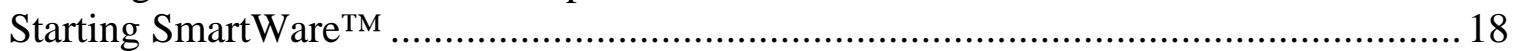

APPENDIX E: SAMPLE FORMS AND REPORTS..................................................... 19

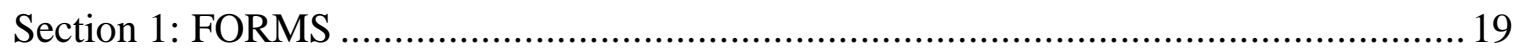

Data Logger Tracking Sheet ............................................................... 19

DATA LOGGER TRACKING SHEET (Sample) ............................... 20

Data Logger Analysis Checklist ................................................................. 21

Data LoggerAnalysis Checklist (SAMPLE) ................................... 22

Section 2: CHARTS PRODUCED BY DESLOG .................................................... 24 
C-4 


\section{TIME-OF-USE (TOU) SMARTLOGGERS ${ }^{\text {TM }}$}

Time-Of-Use (TOU) SmartLoggers detect the actual times a device turns on and off. The on/off transition times are stored in the logger where the data is retrieved and analyzed using the TOU SmartWare ${ }^{T M}$ software. So simple to use, there isn't even a power switch!

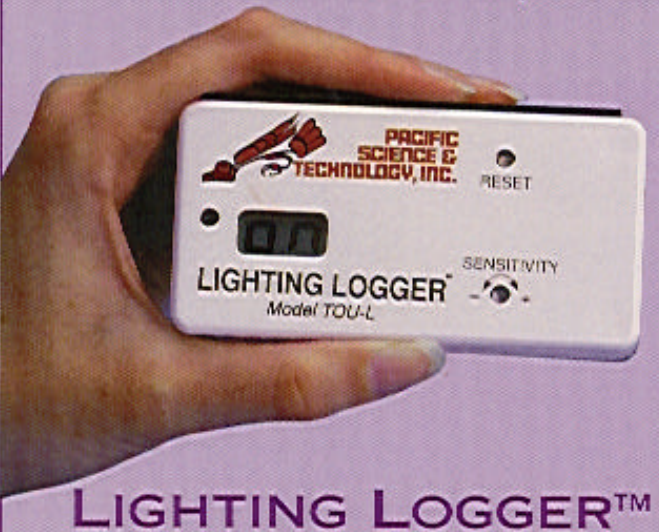

- Evaluate retrofits and verify savings

- Answer peak impact questions

- Calculate energy consumption

- Provide operations feedback to end-users

- Verify the proper operation of energy management systems

- No wiring

- Battery operated - 10 year life

Lighting Loggers have a built-in photocell to record time-of-use light usage and a sensitivity adjustment to eliminate daylight and stray lighting interference. This ensures that only the monitored lights are recorded.

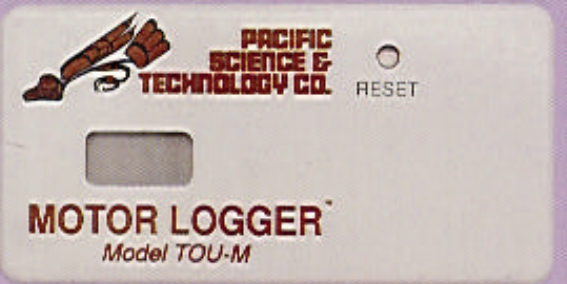

\section{CT LOGGERTM}

CT Loggers use a current transformer that clips over the monitored wire to record time-of-use by detecting the current draw of motors, heat pumps, air conditioners, fans, appliances or other electrical devices.

$c \epsilon$

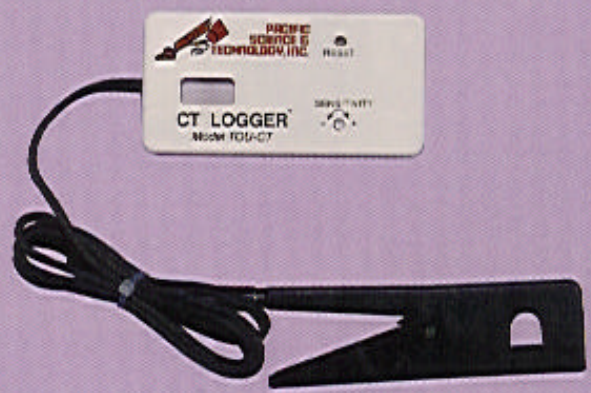

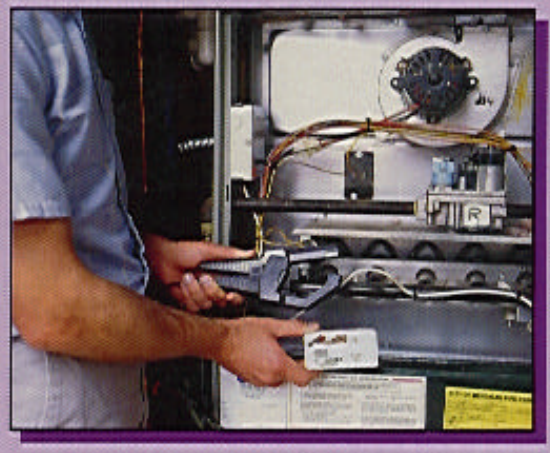

Pacific Science \& Technology 64 NW Franklin Avenue Bend, Oregon 97701 1-800-388-0770 in the USA 541-388-4774 or Fax 541-385-9333 info(pacscitech.com http://www.pacscitech.com 